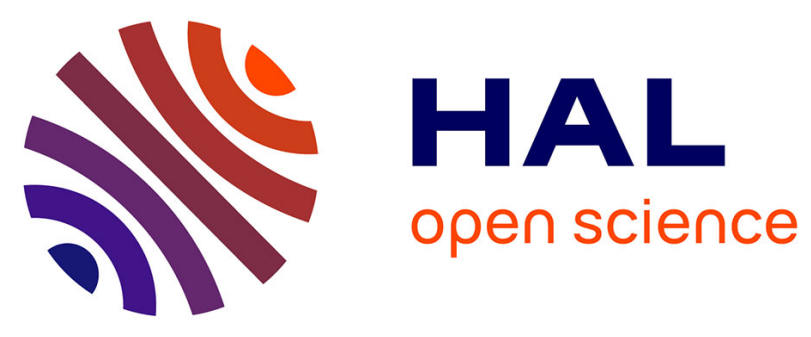

\title{
Effect of CFTR correctors on the traffic and the function of intracellularly retained $\mathrm{ABCB} 4$ variants
}

Amel Ben Saad, Virginie Vauthier, Ágota Tóth, Angelika Janaszkiewicz, Anne-Marie Durand-Schneider, Alix Bruneau, Jean-Louis Delaunay, Martine Lapalus, Elodie Mareux, Isabelle Garcin, et al.

\section{To cite this version:}

Amel Ben Saad, Virginie Vauthier, Ágota Tóth, Angelika Janaszkiewicz, Anne-Marie DurandSchneider, et al.. Effect of CFTR correctors on the traffic and the function of intracellularly retained ABCB4 variants. Liver International, 2021, 41 (6), pp.1344 - 1357. 10.1111/liv.14839 . hal-03263358

\section{HAL Id: hal-03263358 \\ https://hal.sorbonne-universite.fr/hal-03263358}

Submitted on 17 Jun 2021

HAL is a multi-disciplinary open access archive for the deposit and dissemination of scientific research documents, whether they are published or not. The documents may come from teaching and research institutions in France or abroad, or from public or private research centers.
L'archive ouverte pluridisciplinaire HAL, est destinée au dépôt et à la diffusion de documents scientifiques de niveau recherche, publiés ou non, émanant des établissements d'enseignement et de recherche français ou étrangers, des laboratoires publics ou privés. 
PROF. EMMANUEL JACQUEMIN (Orcid ID : 0000-0002-7536-6272)

DR. THOMAS FALGUIÈRES (Orcid ID : 0000-0003-2867-0500)

Article type : Original Articles

Editor : Emma andersson

\section{Effect of CFTR correctors on the traffic and the function of intracellularly retained $\mathrm{ABCB} 4$ variants}

Amel Ben Saad ${ }^{1,2}$, Virginie Vauthier ${ }^{2,3}$, Ágota Tóth ${ }^{4}$, Angelika Janaszkiewicz ${ }^{4}$ AnneMarie Durand-Schneider ${ }^{2}$, Alix Bruneau ${ }^{2,5}$, Jean-Louis Delaunay ${ }^{2}$, Martine Lapalus ${ }^{1}$, Elodie Mareux ${ }^{1}$, Isabelle Garcin ${ }^{1}$, Emmanuel Gonzales ${ }^{1,6}$, Chantal Housset ${ }^{2,7}$, Tounsia Aït-Slimane ${ }^{2}$, Emmanuel Jacquemin ${ }^{1,6}$, Florent Di $\mathrm{Meo}^{4}$, Thomas Falguières ${ }^{1, *}$

1 Inserm, Université Paris-Saclay, Physiopathogénèse et traitement des maladies du foie, UMR_S 1193, Hepatinov, 91400 Orsay, France.

2 Inserm, Sorbonne Université, Centre de Recherche Saint-Antoine (CRSA), UMR_S 938, Institute of Cardiometabolism and Nutrition (ICAN), 75012 Paris, France.

${ }^{3}$ Current address: Université de Paris, Institut Cochin, Inserm U1016, CNRS UMR 8104, 75014 Paris, France.

4 Inserm, Université de Limoges, Faculté de Médecine et de Pharmacie, UMR 1248, Campus Marcland, 87000 Limoges, France.

This article has been accepted for publication and undergone full peer review but has not been through the copyediting, typesetting, pagination and proofreading process, which may lead to differences between this version and the Version of Record. Please cite this article as doi: $\underline{10.1111 / \mathrm{LIV} .14839}$

This article is protected by copyright. All rights reserved 
5 Current address: Department of Hepatology \& Gastroenterology, Charité Universitätsmedizin Berlin, 13353 Berlin, Germany.

6 Assistance Publique - Hôpitaux de Paris, Paediatric Hepatology \& Paediatric Liver Transplant Department, Reference Center for Rare Paediatric Liver Diseases, FILFOIE, ERN Rare-Liver, Faculté de Médecine Paris-Saclay, CHU Bicêtre, 94270 Le Kremlin-Bicêtre, France.

7 Assistance Publique - Hôpitaux de Paris. Hôpital Saint-Antoine, Reference Center for inflammatory biliary diseases and autoimmune hepatitis, FILFOIE, ERN Rare-Liver, 75012 Paris, France.

* Corresponding author: Thomas Falguières, PhD - UMR_S 1193 Inserm / Université Paris Saclay - Rue des Adèles - Bâtiment 440 - F-91405 Orsay cedex, France. Phone : +33-(0)1-69-1562-94. e-mail: thomas.falguieres@inserm.fr

Text electronic word count: 5636 words.

\section{Figures: 6}

Supplementary information: Supplementary Materials and Methods, 6 tables, 5 figures and Supplementary references.

Authorship statement: A.B.S., V.V. and T.F. designed the study. A.B.S., V.V., Á.T., A.J., A.M.D.S. and T.F. performed the experiments. A.B.S., V.V., Á.T., A.J., A.M.D.S., A.B., J.L.D., M.L., E.M., I.G., E.G., C.H., T.A.S., E.J., F.D.M. and T.F. analysed the data and provided intellectual contribution. A.B.S., F.D.M. and T.F. wrote the manuscript, which was reviewed and approved by all authors.

Abbreviations: ABC, ATP-binding cassette; $\mathrm{ABCB} 4^{\mathrm{cc}}, \mathrm{ABCB} 4-\mathrm{closed}$ conformation; $\mathrm{ABCB} 4^{\text {if }}$, ABCB4-inward facing conformation; ATP, adenosine triphosphate; CFTR, cystic fibrosis transmembrane conductance regulator; $\mathrm{Cp}$, coupling helix; ER, endoplasmic reticulum; HEK, human embryonic kidney; NBD, nucleotide binding domain; PC, phosphatidylcholine; PFIC3, progressive familial intrahepatic cholestasis type 3; TM, transmembrane helix; UDCA, ursodeoxycholic acid; WT, wild type.

Conflict of interest: None to declare. 
Financial support: A.B.S. and E.M. were supported by the " Ministère de l'Enseignement Supérieur, de la Recherche et de l'Innovation ». T.F. was supported by grants from the Agence Nationale de la Recherche (ANR-15-CE14-0008-01) and the French Association for the Study of the Liver (AFEF). Á.T., A.J. and F.D.M. were supported by grants from the Agence Nationale de la Recherche (ANR-19-CE17-0020-01 IMOTEP), Région Nouvelle Aquitaine and Institut National de la Santé et de la Recherche Médicale (AAP NA 2019 VICTOR).

Acknowledgements: We are grateful to the Cystic Fibrosis Foundation (https://www.cff.org/) and the CFTR Chemical Compound Program (https://www.cff.org/Research/ResearcherResources/Tools-and-Resources/CFTR-Chemical-Compound-Program/) for providing CFTR correctors. We thank AMFE (Association Maladie Foie Enfants, Malakoff, France), MLD (Monaco Liver disorder, Monaco), Association "Pour Louis 1000 Foie Merci" (Fournet-Luisans, France), Association "Il était un foie" (Plouescat, France) and Fondation Rumsey-Cartier (Genève, Switzerland) for their support. We also thank Wadih Ghattas and Charles Skarbek (Institut de Chimie Moléculaire et des Matériaux d'Orsay, Université Paris-Saclay, Orsay, France) for their help with multiplate fluorescence reading. We are grateful to regional supercomputer CALI (“CAlcul en LImousin”) and Xavier Montagutelli for technical support. 


\section{Abstract}

Background \& aim: ABCB4 is expressed at the canalicular membrane of hepatocytes. This ATPbinding cassette $(\mathrm{ABC})$ transporter is responsible for the secretion of phosphatidylcholine into bile canaliculi. Missense genetic variations of ABCB4 are correlated with several rare cholestatic liver diseases, the most severe being progressive familial intrahepatic cholestasis type 3 (PFIC3). In a repurposing strategy to correct intracellularly retained ABCB4 variants, we tested 16 compounds previously validated as cystic fibrosis transmembrane conductance regulator (CFTR) correctors.

Methods: The maturation, intracellular localization and activity of intracellularly retained ABCB4 variants were analyzed in cell models after treatment with CFTR correctors. In addition, in silico molecular docking calculations were performed to test the potential interaction of CFTR correctors with ABCB4.

Results: We observed that the correctors $\mathrm{C} 10, \mathrm{C} 13$ and $\mathrm{C} 17$, as well as the combinations of $\mathrm{C} 3+\mathrm{C} 18$ and $\mathrm{C} 4+\mathrm{C} 18$, allowed the rescue of maturation and canalicular localization of four distinct traffic-defective ABCB4 variants. However, such treatments did not permit a rescue of the phosphatidylcholine secretion activity of these defective variants and were also inhibitory of the activity of wild type ABCB4. In silico molecular docking analyses suggest that these CFTR correctors might directly interact with transmembrane domains and/or ATP-binding sites of the transporter.

Conclusion: Our results illustrate the uncoupling between the traffic and the activity of ABCB4 since the same molecules can rescue the traffic of defective variants while they inhibit the secretion activity of the transporter. We expect that this study will help to design new pharmacological tools with potential clinical interest.

\section{KEYWORDS}

ABC transporters; Bile secretion; Cell models; Cholestatic liver diseases; Molecular docking; Targeted pharmacotherapy.

\section{LAY SUMMARY}


- CFTR correctors rescue the maturation and the in vitro localization of four distinct ERretained $\mathrm{ABCB} 4$ variants identified in patients.

- CFTR correctors do not rescue the function of these variants even if they are relocalized at the plasma membrane.

- $\quad$ CFTR correctors inhibit the function of wild type ABCB4.

- In silico molecular docking analyses suggest direct interactions of CFTR correctors with functional domains of ABCB4. 


\section{INTRODUCTION}

Bile secretion is an essential function of the liver for lipid digestion and absorption as well as the elimination of xenobiotics and endogenous metabolites. This function mainly depends on transporters localized at the apical (or canalicular) plasma membrane of hepatocytes such as ATPbinding cassette subfamily B member 4 (ABCB4), also known as multidrug resistance protein type 3 (MDR3). ABCB4 belongs to the superfamily of ATP-binding cassette (ABC) transporters which are transmembrane proteins able to bind and hydrolyze ATP in order to fulfil their biological functions ${ }^{1,2}$. The expression of ABCB4 is restricted to the canalicular membrane of hepatocytes ${ }^{3}$ and its role is to ensure secretion of phosphatidylcholine (PC) into bile ${ }^{4}$. With the co-secreted cholesterol and bile salts, PC forms mixed micelles in the aqueous environment of bile, thus avoiding the formation of cholesterol gallstones in the biliary tract as well as cell membrane damage by free bile acids on the canalicular membrane of hepatocytes and the apical membrane of cholangiocytes (for reviews, see ${ }^{1,5}$ ). Until now, more than 220 distinct variations of the ABCB4encoding gene have been reported, mostly in patients with cholestatis and cholelithiasis (see https://evs.gs.washington.edu/EVS/ and http://abcmutations.hegelab.org/). These genetic variations of $\mathrm{ABCB} 4$ can affect the expression, the traffic, the function or the stability of the protein. Indeed, we have previously proposed a classification of these variants into five distinct classes: class I with no protein expression, class II with intracellular retention; class III with functional defects, class IV with stability impairment and class V with no apparent defect ${ }^{6,7}$. More details about ABCB4 function, genetic disorders and subsequent diseases can be found in the recent review by Kroll et al. ${ }^{8}$.

The most severe ABCB4-related disease is progressive familial intrahepatic cholestasis type 3 (PFIC3), which is a rare autosomal recessive disease affecting homozygous or compound heterozygous patients during childhood ${ }^{9}$. PFIC3 appears during the first months of life and is characterized by chronic cholestasis, jaundice and pruritus ${ }^{10}$. The only pharmacological treatment for PFIC3 patients is the administration of ursodeoxycholic acid (UDCA), a bile acid with low hydrophobicity which renders the bile less toxic ${ }^{11,12}$. However, more than half of PFIC3 patients display no or little response to UDCA treatment and worsening of the disease most often requires liver transplantation ${ }^{10,13}$. Therefore, the therapeutic challenge is to identify new targeted 
pharmacotherapies as an alternative to liver transplantation for patients with severe forms of ABCB4-related diseases.

Looking for correctors of class II endoplasmic reticulum (ER)-retained ABCB4 variants, we have recently shown that structural analogues of roscovitine are able to partially rescue the traffic, localization and function of these variants ${ }^{14}$. In the present study, in order to pursue this repositioning strategy, we were interested in correctors previously shown to rescue the plasma membrane targeting of the F508del variant of ABCC7/CFTR (cystic fibrosis transmembrane conductance regulator), the $\mathrm{ABC}$ transporter mutated in patients with cystic fibrosis (see Supplementary Table S1, and references therein). While we observed that CFTR correctors are able to rescue the maturation and the localization of several ER-retained ABCB4 variants, we report that they are not able to rescue their PC secretion activity and that they also inhibit the activity of the wild type transporter. These two effects might be due to direct interactions of CFTR correctors with functional domains of ABCB4 such as transmembrane domains and/or nucleotide binding domains, as suggested by in silico molecular docking calculations. 


\section{MATERIALS AND METHODS}

\section{Plasmids, cell culture and transfection}

Plasmids encoding WT and ER-retained ABCB4 missense variants (I541F, I490T, L556R) have been described ${ }^{14-16}$. The $\mathrm{R} 545 \mathrm{H}$ variant was previously reported ${ }^{17}$ and site-directed mutagenesis was performed as described ${ }^{14}$ using the following primers (Eurogentec, Angers, France): 5'GATCGCCATTGCACATGCCCTGGTTCGCA-3'(forward) and 5 TGCGAACCAGGGCATGTGCAATGGCGATC-3' (reverse). Human embryonic kidney (HEK293, herein referred to as HEK; ATCC $\left(-C R L-1573^{\mathrm{TM}}\right.$ ) cells and human hepatocellular carcinoma HepG2 (ATCC®- HB-8065 ${ }^{\mathrm{TM}}$ ) cells were obtained from ATCC (Manassas, VA). Cells were grown at $37^{\circ} \mathrm{C}$ with $5 \% \mathrm{CO}_{2}$ in Dulbecco's Modified Eagle Medium (Thermo Fisher Scientific,

Villebon-sur-Yvette, France) containing $4.5 \mathrm{~g} / \mathrm{L}$ D-glucose and supplemented with $10 \%$ heatinactivated fetal bovine serum (Sigma, Saint-Quentin Fallavier, France), 2 mM L-glutamine, 2 $\mathrm{mM}$ sodium pyruvate, 100 units $/ \mathrm{mL}$ penicillin and $100 \mu \mathrm{g} / \mathrm{mL}$ streptomycin (Thermo Fisher Scientific). Transient transfections were performed using Turbofect (Thermo Fisher Scientific) at a ratio of reagent:DNA of 2:1 for HEK cells, and JetPrime (PolyPlus Transfection, Illkirch, France) at a ratio of reagent:DNA of 2:1 for HepG2 cells, according to manufacturers' instructions. To maintain similar ABCB4 expression and avoid fluctuation of protein expression levels from one condition to another, cells were split in separated wells only after transfection of the whole population in $10 \mathrm{~cm}$ Petri dishes and overnight expression of the transgene.

\section{Chemicals and cell treatments}

CFTR correctors (see details in Supplementary Table S1) were kindly provided by the CFTR Chemical Compound Program of the Cystic Fibrosis Foundation (Chicago, IL). All compounds were solubilized in dimethylsulfoxide (DMSO) as 1000X concentrated stock solutions in order to treat cells with $10 \mu \mathrm{M}$ final concentration, using DMSO as control vehicle at the same dilution (0.1\% DMSO for all conditions). Twenty-four hours post-transfection (except for cytotoxicity assays), cells were treated during 16 hours with these drugs. After drug treatment, cells were used for cytotoxicity assays, immunoanalyses, or PC secretion assays.

\section{Cytotoxicity assays}


Cytotoxicity of CFTR correctors was assessed by the conversion of MTT (3-[4,5-dimethylthiazol2-yl]-2,5 diphenyl tetrazolium bromide; Sigma) into formazan crystals by living cells, as described $^{18}$. In brief, subconfluent HEK cells were plated in 96-well plates in triplicate for each tested condition, including controls (no cells, treatment with vehicle only). Eight hours after cell seeding and 16 hours after drug treatment, $125 \mu \mathrm{g} / \mathrm{mL}$ MTT (final concentration) was added in each well and cells were re-incubated at $37^{\circ} \mathrm{C}$ for 2 hours. Then culture media were gently washed out, cells were lysed in $100 \mu \mathrm{L}$ of DMSO and absorbance at $540 \mathrm{~nm}$ was measured using a multiplate cytofluorimeter SpectraFluor from Tecan (Männedorf, Switzerland). Cytotoxicities were calculated for each triplicate and after background subtraction, means were expressed as percentages of the mean for cells treated with vehicle only.

\section{Immunoblots, immunofluorescence and measurement of ABCB4-mediated phosphatidylcholine secretion}

Immunoblots and indirect fluorescence analyses were performed as previously described ${ }^{14}$, using the following primary antibodies: mouse monoclonal anti-ABCB4 (clone $\mathrm{P}_{3} \mathrm{II}-26$ ) and antiABCC2 (clone M2I-4) from Enzo Life Sciences (Villeurbanne, France); anti- $\alpha$-tubulin (clone 1E4C11) from ProteinTech (Manchester, United Kingdom). Peroxidase- and fluorochromeconjugated secondary antibodies were from Sigma and Thermo Fisher Scientific, respectively. Immunoblots were quantified in the linear range of detection using ImageJ 1.50i software (U.S. National Institutes of Health, Bethesda, MD). Immunofluorescence images were acquired using a confocal microscope (Eclipse TE-2000-Nikon-C2) equipped with a $60 \mathrm{X}$ objective, serial xy optical sections with a z-step of $0.3 \mu \mathrm{m}$ were taken using Nikon NIS-Elements software version AR 4.50 with constant settings (laser powers and correction of signal intensities) and treated using Adobe Photoshop version 8.0.1. Measurement of ABCB4-mediated PC secretion using a fluoroenzymatic assay was performed as described ${ }^{19}$. Each condition was analysed in triplicate and the secreted PC was calculated as follows:

$$
N_{x}=\frac{\left(V_{x+}-V_{b g r d+}\right)-\left(V_{x-}-V_{b g r d-}\right)}{A}
$$

with $N_{x}$ the amount of PC in nmol; $V_{x \text { - }}$ and $V_{x+}$ the fluorescence means for the tested condition in the absence or presence of phospholipase D, respectively; $V_{\text {bgrd }}$ and $V_{\text {bgrd }}$ the background fluorescence means in the absence or presence of phospholipase $\mathrm{D}$, respectively; A the slope of the 
standard curve (in AU.nmol ${ }^{-1}$ ). Then, results were expressed as percentages of wild type ABCB4 (ABCB4-WT) activity as follows:

$$
M_{x}=\frac{N_{x}-N_{\text {mock }}}{N_{W T}-N_{\text {mock }}} \times \frac{D_{W T}}{D x} \times 100
$$

with $M_{x}$ the PC secretion activity as a percentage of ABCB4-WT activity; $N_{x}, N_{\text {mock }}$ and $N_{W T}$ the amounts of secreted PC for the tested condition, mock-transfected cells and ABCB4-WT expressing cells, respectively, according to (1); $D_{x}$ and $D_{W T}$ the expression levels of mature ABCB4 determined by densitometry analysis from immunoblots with the corresponding cell lysates for the tested condition and ABCB4-WT expressing cells, respectively.

\section{In silico molecular docking and calculations}

Two conformations of human ABCB4 (hABCB4) were considered for molecular docking calculations, namely inward-facing and closed conformations $\left(\mathrm{ABCB} 4^{\mathrm{if}}\right.$ and $\mathrm{ABCB} 4^{\mathrm{cc}}$, respectively). $\mathrm{ABCB} 4{ }^{\mathrm{if}}$ was built by homology modelling using the inward-facing human $\mathrm{ABCB} 1$ $(h \mathrm{ABCB} 1)$ protein data bank structure (PDB ID: 6QEX) ${ }^{20}$, given the high sequence identity between $h \mathrm{ABCB} 1$ and $h \mathrm{ABCB} 4\left(76.8 \%\right.$, see Supplementary Figure S1). ABCB4 ${ }^{\mathrm{cc}}$ model was built using the recently resolved cryo-EM structure of ABCB4 ${ }^{\mathrm{cc}}$ structure trapped in ATP-bound state (PDB ID: 6S7P) ${ }^{21}$. The non-resolved extracellular loop (residues 85-104) of ABCB4 ${ }^{\text {cc }}$ was built based on the resolved $h \mathrm{ABCB} 1$ structure. For both models, $\mathrm{L}_{1}$-linker connecting nucleotide binding domain (NBD) 1 to transmembrane helix (TM) 7, and the $\mathrm{N}$ - and C-terminal domains were not included in the present study owing to their absence in both resolved $h \mathrm{ABCB} 1$ and hABCB4 structures (Supplementary Figure S1). Present models did not include the ATP molecules. Homology modeling were performed using the Modeller software version 9.2322-24. Prior to docking calculations, both models were minimized in solvated membrane lipid bilayers that were removed for docking calculations (for further details, see Supplementary Materials and Methods). 
Molecular docking calculations were carried out using the Autodock Vina software ${ }^{25}$. Given the absence of a priori knowledge about the interaction mechanism of CFTR correctors, the following procedure was performed to extensively sample plausible binding sites of CFTR correctors to both $\mathrm{ABCB} 44^{\mathrm{if}}$ and $\mathrm{ABCB} 4{ }^{\mathrm{cc}}$ conformers. First, so-called "blind" docking calculations were performed with all ligands in which the whole protein was considered as intentionally too large volume search space centered on the protein center of mass for both $\mathrm{ABCB} 4^{\mathrm{if}}$ and $\mathrm{ABCB} 4^{\mathrm{cc}}$ conformations (Supplementary Table S2A). A set of 20 replicas per CFTR corrector was performed, using different random seeds, providing a total of approximately 6400 poses per ABCB4 conformation. These molecular poses exhibited clusters located at different spatial regions (see Supplementary Figure S2). Refined docking calculations were then performed in which smaller space search volumes were used (Supplementary Figure S3), which do not exceed the recommended search volume of $27000 \AA^{3}$ to ensure the reliability of docking calculation results. Again, 20 replicas of refined molecular docking calculations were performed for each CFTR corrector. For blind and refined docking calculations, exhaustiveness was set to 40 and 100, respectively, in order to increase the computational effort used during molecular pose $\operatorname{search}^{26}$. The maximum number of poses was set to 100 by replica and the initial affinity cutoff was defined at $15 \mathrm{kcal}^{\mathrm{mol}}{ }^{-1}$ with respect to the top pose of a given replica. The list of flexible residues allowed for each volume search space is reported in Supplementary Table S2B. Given the large number of plausible flexible residues, only sidechain $\mathrm{C}_{\beta}-\mathrm{C}_{\gamma}$ bonds were allowed to rotate as a compromise within the limit of 32 rotatable bonds allowed by Autodock Vina software.

Additional information about $\mathrm{ABCB} 4$ and ligand preparations as well as analyses are provided in Supplementary Materials and Methods.

\section{Statistics}

Graphics and one-way ANOVA tests were performed using Prism version 7.00 (GraphPad Software, La Jolla, CA). A $P$ value of less than 0.05 was considered significant with *: $\mathrm{p}<0.05$;

**: $\mathrm{p}<0.01$; ***: $\mathrm{p}<0.005$; ns: not significant. Symbols always indicate the comparison between the control (vehicle-treated) and the other tested conditions. 


\section{ReSUlts}

\section{CFTR correctors rescue the traffic of the ER-retained I541F variant of ABCB4}

In order to identify new pharmacological correctors for ER-retained ABCB4 variants, we tested the possibility to repurpose CFTR correctors previously reported to rescue the plasma membrane targeting of F508del-CFTR. We tested the effect of 16 CFTR correctors (Supplementary Table S1). Using MTT assay, we first ascertained that none of these molecules were cytotoxic after 16 hours of treatment at $10 \mu \mathrm{M}$ in HEK cells (Figure 1). As a model of ER-retention of ABCB4, we used the well-characterized $\mathrm{I} 541 \mathrm{~F}$ variant, for which plasma membrane targeting could be restored at low temperature $\left(27^{\circ} \mathrm{C}\right)$ and by pharmacological means ${ }^{14-16}$. On immunoblots from HEK cell lysates, ABCB4-I541F is mainly present at an apparent molecular weight of $140 \mathrm{kDa}$ due to its incomplete glycosylation, by opposition to ABCB4-WT mainly present as a fully glycosylated protein with an apparent molecular weight of $160 \mathrm{kDa}$ (Figure 2A), as previously demonstrated ${ }^{15}$. After 16 hours of cell treatment with $10 \mu \mathrm{M}$ of the different CFTR correctors, we observed that some of them were able to correct ABCB4-I541F maturation, considering the increased amounts of its mature form (Figure 2A). The quantification of these results indicated that C10 (KM11057), $\mathrm{C} 13$ (Corr-4C) and $\mathrm{C} 17(15 \mathrm{jF})$ were the best ABCB4 corrector candidates, as well as combinations of C3+C18 (VRT-325+VRT-534) and C4+C18 (Corr4A+VRT-534) (Figure 2B), previously reported to be able to rescue F508del-CFTR as well as defective ABCA4 variants ${ }^{27,28}$. We then investigated the potential of these correcting molecules to restore canalicular targeting of ABCB4-I541F in HepG2 cells, a human hepatoma-derived cell line forming pseudo-bile canaliculi in culture $^{29}$. In these polarized cells, ABCB4-WT colocalized with ABCC2 at bile canaliculi, which was not the case of ABCB4-I541F displaying a diffuse cytoplasmic staining (Figure 2C). However, after 16 hours of treatment with $10 \mu \mathrm{M}$ of $\mathrm{C} 10, \mathrm{C} 13, \mathrm{C} 17$, or the $\mathrm{C} 3+\mathrm{C} 18$ and $\mathrm{C} 4+\mathrm{C} 18$ combinations, canalicular staining of ABCB4-I541F was rescued, as shown by its colocalization with $\mathrm{ABCC} 2$ (Figure 2C). Altogether, these results indicate that $\mathrm{C} 10, \mathrm{C} 13, \mathrm{C} 17$, and $\mathrm{C} 3+\mathrm{C} 18$ and $\mathrm{C} 4+\mathrm{C} 18$ combinations are able to partially rescue the maturation and the canalicular localization of ABCB4-I541F.

This article is protected by copyright. All rights reserved 
CFTR correctors also rescue the maturation and the localization of three other ER-retained ABCB4 variants

In order to determine if these CFTR corrector candidates might be envisioned as general correctors for ER-retained ABCB4 variants, we investigated their effect on three other ABCB4 variants (I490T, R545H, L556R), previously reported in patients with liver diseases ${ }^{9,17,30}$, and already shown to be class II ER-retained for the I490T and L556R variants ${ }^{6,14}$. Our results give evidence that $\mathrm{C} 10, \mathrm{C} 13, \mathrm{C} 17$, and $\mathrm{C} 3+\mathrm{C} 18$ and $\mathrm{C} 4+\mathrm{C} 18$ combinations are also able to rescue the maturation of these three immature variants (Figure 3A-C). The quantifications of these experiments indicate that rescuing efficiencies were all statistically significant, even though efficiencies vary among the three variants (Figure 3D-F). As performed for ABCB4-I541F, we analysed the intracellular localization of these three variants in HepG2 cells. After vehicle treatment, ABCB4-I490T, $\mathrm{R} 545 \mathrm{H}$ and -L556R do not colocalize with ABCC2 (Figure 3G-I, upper panels). But after treatment with $\mathrm{C} 10, \mathrm{C} 13$ or $\mathrm{C} 17$, as well as with $\mathrm{C} 3+\mathrm{C} 18$ or $\mathrm{C} 4+\mathrm{C} 18$ combinations, the localization of the three variants at bile canaliculi was rescued (Figure 3G-I). Thus, these CFTR correctors are able to rescue the maturation and the localization of four distinct ER-retained $\mathrm{ABCB} 4$ variants, suggesting that they trigger common correcting molecular mechanisms.

CFTR correctors do not restore the function of ER-retained ABCB4 variants and inhibit ABCB4-WT function

The aim of correcting the intracellular traffic of ER-retained ABCB4 variants is to obtain sufficient amounts of functional transporters present at the plasma membrane in order to rescue PC secretion in the extracellular space. Using a previously described fluoro-enzymatic approach ${ }^{19}$, we measured ABCB4-mediated PC secretion of the four variants transiently expressed in HEK cells with or without treatment with the different CFTR correcting drugs. As expected, we observed a strongly reduced activity (less than 10-15\% of ABCB4-WT activity) for the four variants in the absence of treatment by comparison to ABCB4-WT (Figure 4A-D). Nevertheless, none of the CFTR correctors (used alone or in combination) was able to significantly rescue the function of any of the four variants (Figure 4A-D), despite their partial rescue of maturation and canalicular localization (Figures 2 and 3). Instead, we observed a trend towards less activity in treated cells, 
even if differences did not reach statistical significance (Figure 4A-D). We also tested these CFTR correctors in HEK cells expressing ABCB4-WT. Surprisingly, we observed that $10 \mu \mathrm{M}$ of C10, $\mathrm{C} 13, \mathrm{C} 17, \mathrm{C} 3+\mathrm{C} 18$ or $\mathrm{C} 4+\mathrm{C} 18$ dramatically inhibited ABCB4-WT activity to less than $10 \%$ of its maximal activity (Figure 4E). Similar inhibitory effects of these CFTR correctors were also observed on ABCB4-WT when used at $5 \mu \mathrm{M}$ (data not shown). A possible interaction of CFTR correctors with membrane lipids leading in fine to their release into the extracellular medium is unlikely or negligible since our results indicate that ABCB4-WT-mediated PC secretion is dramatically reduced to $1.6-6.0 \%$ of control activity after treatment with these compounds (Figure 4E). Altogether, our results provide evidence that, despite their capacity to restore ABCB4 targeting at the canalicular membrane, the CFTR correctors investigated here also inhibit PC secretion function mediated by the transporter.

\section{Molecular docking calculations reveal different plausible binding regions of CFTR correctors within $A B C B 4$}

We hypothesized that the inhibition of ABCB4 activity by CFTR correctors could be related to their direct interaction with functional domains of the transporter. To test this possibility, we performed in silico molecular docking simulations. Blind calculations were first performed using large box parameters (Supplementary Table S2A) with inward-facing ABCB4 (ABCB4 ${ }^{\text {if }}$ ) and its closed conformation $\left(\mathrm{ABCB} 4^{\mathrm{cc}}\right.$ ) wherein no a priori plausible structural binding regions were defined (for details, see Materials and Methods). This provided 6398 and 6395 molecular poses for $\mathrm{ABCB} 4^{\mathrm{if}}$ and $\mathrm{ABCB} 4^{\mathrm{cc}}$, respectively. Molecular poses were then spatially clustered, revealing a single binding site for CFTR correctors within $\mathrm{ABCB} 4{ }^{\mathrm{if}}$ while three binding sites were obtained for $\mathrm{ABCB} 4^{\mathrm{cc}}$ (Supplementary Figure S2). In ABCB4 $4^{\mathrm{if}}, 95 \%$ of molecular poses are located in ABCB4 protein chamber (Supplementary Table S3), expected to be the canonical phospholipid binding site region ${ }^{21}$. Regarding $\mathrm{ABCB} 4^{\mathrm{cc}}, 81 \%$ of molecular poses can be initially divided into three distinct regions, namely an alternative site at the lipid-protein interface $(30 \%$ of molecular poses) and the two known ATP-binding sites at both NBD interfaces (15 and $36 \%$ for ATPbinding sites 1 and 2, respectively - see Supplementary Table S3). Given the low sensitivity of blind docking calculations, regions obtained from blind docking calculations on ABCB4 ${ }^{\text {if }}$ were also explored for refined docking calculations on $\mathrm{ABCB} 4^{\mathrm{cc}}$ and vice versa (Supplementary Figure 
S3). It is worth mentioning that no molecular poses were observed for ATP-binding site regions on $\mathrm{ABCB} 4^{\mathrm{if}}$, which makes sense considering the large distance between the two NBDs in this conformation. Altogether, refined molecular docking calculations on ABCB4 ${ }^{\text {if }}$ highlights the relevance of the so-called protein chamber (Figure 5A). Regarding ABCB4 $4^{\text {cc }}$, molecular docking calculations suggested six possible regions for CFTR corrector binding; namely protein chamber, ATP-binding sites 1 and 2 and three alternative sites 1,2 and 3 at the lipid protein interface (Supplementary Figure S3 and Figure 5A).

Thorough analysis over all molecular poses were then performed for each binding site to stress out key residues possibly involved in CFTR corrector binding to ABCB4. Only poses exhibiting binding affinity difference with respect to top-ranked molecular poses below $2.0 \mathrm{kcal} . \mathrm{mol}^{-1}$ were considered as already described ${ }^{31}$. In total, a set of 38670 molecular poses over 50482 were obtained from refined molecular docking calculations (Supplementary Table S4). Accounting aforementioned in vitro results, special attention was paid to selected CFTR correctors, namely $\mathrm{C} 3, \mathrm{C} 4, \mathrm{C} 10, \mathrm{C} 13, \mathrm{C} 17$ and $\mathrm{C} 18$ (Figure 5A). Contact analyses using a $4.5 \AA$ cutoff were performed allowing to decipher key residues to CFTR corrector binding in the four regions of interest in ABCB4 (Figure 5B). It is worth mentioning that contact analyses performed over the whole set of CFTR correctors exhibit similar profiles with respect to selected CFTR correctors (Supplementary Figure S4). Eleven residues are in contact with the selected CFTR correctors in at least $50 \%$ of calculated molecular poses, in $\mathrm{ABCB} 4{ }^{\text {if }}$ protein chamber (Figure $5 \mathrm{~B}$ ). Most of these residues are either aromatic (histidine, phenylalanine and tyrosine) or aliphatic (alanine, leucine), and presumably involved in substrate binding (Figure 6A), as proposed recently for His989 and Ala990 ${ }^{21}$ in $\mathrm{ABCB} 4{ }^{\text {if }}$ protein chamber (underlined residues in Figure 6A). Molecular docking calculations in $\mathrm{ABCB} 4^{\mathrm{cc}}$ alternative site 1 clearly suggested the key role of Val192, Phe195, Ile354 and Phe357 for which contacts are higher than 90\% (Figures 5B and 6A). Likewise, binding to alternative sites 2 and 3 involved mostly contacts with aliphatic residues (Leu842, Val864, Ile867, Ala868, Leu987, Ala990, Ser991 and Ala994 for alternative site 2 and Leu724, Ala727 and Leu761 for alternative site 3). Contact analyses of ABCB4 ${ }^{c c}$ ATP-binding sites and protein chamber exhibited more residues per site owing to smaller volumes as well as more important steric hindrance. Indeed, molecular docking calculations revealed seventeen, ten and seven residues for which contact rate is higher than $90 \%$ in $\mathrm{ABCB} 4^{\mathrm{cc}}$ protein chamber, ATPbinding sites 1 and 2, respectively (Figure 5B). Regarding ATP-binding sites, residue profile again 
included aromatic amino acids (e.g. NBD A-loop residues Tyr403 and Tyr1043) but also polar residues such as arginine (Arg406 and Arg1046) (Figure 6A). Residue profile for ABCB4 ${ }^{\text {cc }}$ protein chamber included mostly polar and aliphatic residues (see Figures 5B and 6A). For all $\mathrm{ABCB} 4$ binding sites, thorough analyses of non-covalent interactions (H-bond and van der Waals interactions) were performed, highlighting the key role of $\pi$-stacking interactions between CFTR correctors' aromatic rings and ABCB4 aromatic residues (Supplementary Table S5). This was clearly shown for ABCB4 ${ }^{\mathrm{cc}}$ alternative site 1 and ATP-binding sites 1 and 2 for which Phe195, Phe357, Tyr403 or Tyr1043 are involved in all $\pi$-stacked conformations. To a lesser extent, Hbonding were also shown to be relevant. For instance, H-bonding with Gln725 were involved in $21 \%$ of molecular poses in ABCB4 $4^{\text {if }}$ protein chamber. Likewise, H-bonding between CFTR correctors and Arg904 (ABCB4 ${ }^{\mathrm{cc}}$ ATP-binding site 1), Arg1046, or Glu1080 (ABCB4 ${ }^{\mathrm{cc}}$ ATPbinding site 2 ) are involved in 27,21 and $21 \%$ of molecular poses, respectively (Supplementary Table S5).

Finally, molecular docking calculations and aforementioned atomic-scaled analyses allowed to define putative binding sites in terms of secondary structure (Supplementary Table S6). ABCB4 ${ }^{\text {if }}$ protein chamber involved the lipid-embedded regions of all TMs but TM11, (Figure 6B). $\mathrm{ABCB} 4^{\mathrm{cc}}$ alternative site 1 is defined by TM1, TM3, TM4 and TM6 (Figure 6B). Alternative sites 2 and 3 are located on the other side of ABCB4 ${ }^{\mathrm{cc}}$, involving TM1, TM4-6, TM7-9 and TM12 for site 2 and TM9, TM10-12 for site 3. Alternative sites 1 and 2 are interfacing with lower leaflet membrane while alternative site 3 is in contact with upper leaflet membrane. In addition to known residues involved in ATP binding, $\mathrm{ABCB} 4^{\mathrm{cc}}$ ATP-binding site regions were also defined, including the coupling helices $(\mathrm{CH})$, namely CHs between TM2 and 3 and TM10 and 11 for ATPbinding site 1, and CHs between TM4 and 5 and TM8 and 9 for ATP-binding site 2 (Figure 6B). Altogether, these in silico molecular docking analyses suggest that CFTR correctors might directly interact with functional domains of ABCB4, which could explain their effect on ABCB4 activity. 


\section{Discussion}

Genetic variations of the phospholipid floppase ABCB4 are correlated with rare cholestatic liver diseases, the most severe form being PFIC3. Some of these genetic variations can cause ABCB4 misfolding, its retention in the ER and, as a result, the loss of its phospholipid floppase function ${ }^{6}$. In previous studies, we and others have demonstrated that small molecules such as cyclosporins $^{6,16}$, 4-phenylbutyrate (4-PBA), curcumin $^{32}$ and structural analogues of roscovitine ${ }^{14}$ are able to partially rescue the intracellular traffic and the cell surface localization of ER-retained ABCB4 variants. However, cytotoxicity, inhibitory effect on ABCB4 function ${ }^{33}$, bioavailability or the high used concentration of these molecules are major limitations for their therapeutic use. In the present study, in order to identify new correctors for ER-retained ABCB4 variants, we explored the potential effect of several molecules, developed as CFTR correctors, on four distinct ER-retained ABCB4 variants identified in patients (I490T, I541F, R545H, L556R mapped in Supplementary Figure S5). CFTR correctors, which were used in this study are small molecules, mostly identified by high-throughput screening strategies to correct the traffic of F508del-CFTR, the most frequent genetic variation detected in patients with cystic fibrosis ${ }^{34}$. The extended use of these correctors is an attractive option for multiple rare diseases associated with protein misfolding and missorting. Interestingly, some of these molecules have been shown to successfully correct the intracellular localization and the function of other defective $\mathrm{ABC}$ transporters such as $\mathrm{ABCA} 3^{35}$ and $\mathrm{ABCA} 4^{28}$ and also ER-retained variants of ATP8B1 ${ }^{36}$ and $\alpha$-sarcoglycan ${ }^{37}$, proteins without CFTR similarity. Here, we show that the correctors C10, C13 and C17 as well as the combinations of $\mathrm{C} 3+\mathrm{C} 18$ and $\mathrm{C} 4+\mathrm{C} 18$ can partially rescue the maturation and the plasma membrane targeting of four defective ABCB4 variants. Further investigations at the molecular level will be required to determine the capacity of these CFTR correctors to rescue a proper folding of the class II ERretained $\mathrm{ABCB} 4$ variants studied here, thus allowing their plasma membrane targeting. The fact that the floppase activity of the I541F, I490T and L556R variants of ABCB4 can be partially rescued by roscovitine analogues ${ }^{14}$ indicates that these missense variants have intrinsic activity once rescued at the plasma membrane. However, the CFTR correctors tested here are not able to restore the function of the ER-retained ABCB4 variants and they also inhibit the floppase activity of ABCB4-WT. While none of the compounds used in this study have been tested in vivo or in clinics, it is interesting to note that rare cases of cholestasis have been reported in patients taking sildenafil ${ }^{38,39}$, the parent molecule of $\mathrm{C} 9$ and $\mathrm{C} 10$, as well as cystic fibrosis patients treated with 
Orkambi, which contains VX-809/Lumacaftor - a derivative from C18/VX-534 (https://www.ema.europa.eu/en/documents/product-information/orkambi-epar-productinformation_en.pdf), arguing for a potential inhibitory effect of these molecules on canalicular ABC transporters.

It is noteworthy to mention that this is not the first time that inhibitory effects of correctors on ABCB4 function are reported. Indeed, cyclosporin A, roscovitine and triazole compounds such as itraconazole were shown to inhibit ABCB4 floppase activity ${ }^{14,33,40}$. Sildenafil, the C10 parent molecule, has also been shown to inhibit the transport function of $\mathrm{ABCB} 1^{41}$, which exhibits $86 \%$ sequence-based similarity with $\mathrm{ABCB} 44^{42}$. The PgpRules prediction tool (https://pgprules.cmdm.tw/) 43 indicates that C3, C4, C10, C13, C17 and C18 might inhibit ABCB1 (data not shown), suggesting similar inhibitory mechanisms on ABCB4. It is important to note that PgpRules prediction tool is initially designed to predict ABCB1 inhibition. Given (i) the high sequence-based similarity between both transporters and (ii) the inhibitor overlaps for both transporters, one can expect that they might, at least partially, share inhibition mechanisms, despite the divergence of substrates translocated by these two transporters ${ }^{8}$. Furthermore, even if CFTR correctors belong to different chemical classes (quinolines, bithiazoles, quinazolines, pyrimidines $)^{34}$, they share features with pharmacophore models of ABCB1 inhibitors previously described as hydrophobic, hydrogen bond acceptor, aromatic ring centered with positive ionizable moieties $^{44}$.

To explain how these CFTR correctors could correct missorting of ABCB4 variants and at the same time inhibit the floppase activity of the transporter, we suggest that these small molecules may directly interact with ABCB4. Such an interaction has already been reported for C18 with $\mathrm{CFTR}^{45}$. To virtually test this hypothesis, we investigated the putative binding sites of CFTR correctors in ABCB4 by in silico docking simulations. Using two models of human ABCB4 in inward-facing and closed conformations $\left(\mathrm{ABCB} 4^{\mathrm{if}}\right.$ and $\mathrm{ABCB} 4^{\mathrm{cc}}$, respectively), we identified seven distinct plausible binding regions for CFTR correctors: protein chambers in both ABCB4 ${ }^{\text {if }}$ and $\mathrm{ABCB} 4{ }^{\mathrm{cc}}$ models; and three alternative sites at the protein-lipid interface and two ATPbinding sites in $\mathrm{ABCB} 4^{\mathrm{cc}}$. Analysis of contact residues with a $4.5 \AA$ cutoff around the docked poses of CFTR correctors indicated that several key residues could be involved in CFTR corrector binding. In ABCB4 $4^{\text {if }}$, we identified His 989 and Ala990 as potential interactors with CFTR correctors, these residues having been recently shown to be crucial for PC binding and ABCB4 
function $^{21}$. We also detected Gln725, a residue conserved in ABCB1 and implicated in the binding of tariquidar ${ }^{46}$. Concerning $\mathrm{ABCB} 4^{\mathrm{cc}}$, we identified Phe357, Tyr403 and Arg1046 located in the alternative site 1, the ATP binding sites 1 and 2, respectively. These three residues were previously reported to be mutated in patients suffering from PFIC3 and low-phospholipid associated cholelithiasis syndrome ${ }^{47-49}$, suggesting their important role in ABCB4 expression and function. Moreover, Tyr403 and Arg1046 were also reported to be essential for ATP binding and hydrolysis ${ }^{21,50}$. It is thus tempting to speculate that the predicted direct interaction of CFTR correctors with key residues of ABCB4 may preclude its phospholipid floppase activity. This view is supported by the fact that sildenafil (the C10 parent molecule) and C3 impair the function of ABCB1 and CFTR, respectively ${ }^{41,51}$. It is important to note that present molecular docking calculations should be considered as an "idea generator" rather than a strong prediction. Thus, these aspects will require further joint experimental and theoretical confirmations, including $\mu$ sscaled molecular dynamics simulations. However, in silico findings might help in the design of site-directed mutagenesis variants to decipher small molecule-dependent inhibition mechanisms of ABCB4.

We propose that the trafficking rescue of ABCB4 variants mediated by CFTR correctors may be conferred through their direct interaction with critical domains of ABCB4, as suggested by our in silico docking analyses. We expect that our findings will help to design new non-inhibitory $\mathrm{ABCB} 4$ correctors that may lead to the preclinical development of pharmacological alternative to UDCA treatment and liver transplantation. Indeed, if our hypothesis is confirmed, the next challenge will be to identify small molecules able to promote folding and trafficking of defective variants without compromising their activity. Thus, further investigations are eagerly needed in order to optimize bioavailability and affinity of these correctors, not only to promote traffic correction but also to maintain the function of the transporter.

This article is protected by copyright. All rights reserved 


\section{REFERENCES}

1. Falguières T, Aït-Slimane T, Housset C, Maurice M. ABCB4: insights from pathobiology into therapy. Clin Res Hepatol Gastroenterol. 2014;38(5):557-563.

2. Srikant S, Gaudet R. Mechanics and pharmacology of substrate selection and transport by eukaryotic ABC exporters. Nature structural \& molecular biology. 2019;26(9):792-801.

3. Smit JJ, Schinkel AH, Mol CA, et al. Tissue distribution of the human MDR3 Pglycoprotein. Lab Invest. 1994;71(5):638-649.

4. Smit JJ, Schinkel AH, Oude Elferink RP, et al. Homozygous disruption of the murine mdr2 P-glycoprotein gene leads to a complete absence of phospholipid from bile and to liver disease. Cell. 1993;75(3):451-462.

5. Boyer JL. Bile formation and secretion. Compr Physiol. 2013;3(3):1035-1078.

6. Delaunay JL, Durand-Schneider AM, Dossier C, et al. A functional classification of ABCB4 variations causing progressive familial intrahepatic cholestasis type 3 . Hepatology. 2016;63(5):1620-1631.

7. Vauthier V, Housset C, Falguieres T. Targeted pharmacotherapies for defective ABC transporters. Biochem Pharmacol. 2017;136:1-11.

8. Kroll T, Prescher M, Smits SHJ, Schmitt L. Structure and Function of Hepatobiliary ATP Binding Cassette Transporters. Chemical reviews. 2020.

9. Jacquemin E, De Vree JM, Cresteil D, et al. The wide spectrum of multidrug resistance 3 deficiency: from neonatal cholestasis to cirrhosis of adulthood. Gastroenterology. 2001;120(6):1448-1458.

10. Jacquemin E. Progressive familial intrahepatic cholestasis. Clin Res Hepatol Gastroenterol. 2012;36 Suppl 1:S26-35.

11. Poupon R. Ursodeoxycholic acid and bile-acid mimetics as therapeutic agents for cholestatic liver diseases: An overview of their mechanisms of action. Clin Res Hepatol Gastroenterol. 2012;36 Suppl 1:S3-S12.

12. Achufusi TGO, Safadi AO, Mahabadi N. Ursodeoxycholic Acid. In: StatPearls. Treasure Island (FL): StatPearls Publishing. 2020.

13. Davit-Spraul A, Gonzales E, Baussan C, Jacquemin E. The spectrum of liver diseases related to ABCB4 gene mutations: pathophysiology and clinical aspects. Semin Liver Dis. 2010;30(2):134-146. 
14. Vauthier V, Ben Saad A, Elie J, et al. Structural analogues of roscovitine rescue the intracellular traffic and the function of ER-retained ABCB4 variants in cell models. Sci Rep. 2019;9(1):6653.

15. Delaunay JL, Durand-Schneider AM, Delautier D, et al. A missense mutation in ABCB4 gene involved in progressive familial intrahepatic cholestasis type 3 leads to a folding defect that can be rescued by low temperature. Hepatology. 2009;49(4):1218-1227.

16. Gautherot J, Durand-Schneider AM, Delautier D, et al. Effects of Cellular, chemical and pharmacological chaperones on the rescue of a trafficking-defective mutant of the ATPbinding cassette transporters ABCB1/ABCB4. J Biol Chem. 2012;287(7):5070-5078.

17. Poupon R, Rosmorduc O, Boelle PY, et al. Genotype-phenotype relationships in the lowphospholipid associated cholelithiasis syndrome. A study of 156 consecutive patients. Hepatology. 2013;58(3):1105-1110.

18. van Meerloo J, Kaspers GJ, Cloos J. Cell sensitivity assays: the MTT assay. Methods Mol Biol. 2011;731:237-245.

19. Gautherot J, Delautier D, Maubert MA, et al. Phosphorylation of ABCB4 impacts its function: Insights from disease-causing mutations. Hepatology. 2014;60(2):610-621.

20. Alam A, Kowal J, Broude E, Roninson I, Locher KP. Structural insight into substrate and inhibitor discrimination by human P-glycoprotein. Science. 2019;363(6428):753-756.

21. Olsen JA, Alam A, Kowal J, Stieger B, Locher KP. Structure of the human lipid exporter ABCB4 in a lipid environment. Nature structural \& molecular biology. 2019;27(1):62-70.

22. Šali A, Blundell TL. Comparative Protein Modelling by Satisfaction of Spatial Restraints. Journal of Molecular Biology. 1993;234(3):779-815.

23. Fiser A, Do RKG, Šali A. Modeling of loops in protein structures. Protein Science. 2000;9(9):1753-1773.

24. Martí-Renom MA, Stuart AC, Fiser A, Sánchez R, and FM, Šali A. Comparative Protein Structure Modeling of Genes and Genomes. Annual Review of Biophysics and Biomolecular Structure. 2000;29(1):291-325.

25. Trott $\mathrm{O}$, Olson AJ. AutoDock Vina: improving the speed and accuracy of docking with a new scoring function, efficient optimization, and multithreading. J Comput Chem. 2010;31(2):455-461. 
26. Forli S, Huey R, Pique ME, Sanner MF, Goodsell DS, Olson AJ. Computational proteinligand docking and virtual drug screening with the AutoDock suite. Nature Protocols. 2016;11(5):905-919.

27. Lopes-Pacheco M, Boinot C, Sabirzhanova I, Morales MM, Guggino WB, Cebotaru L. Combination of Correctors Rescue DeltaF508-CFTR by Reducing Its Association with Hsp40 and Hsp27. J Biol Chem. 2015;290(42):25636-25645.

28. Sabirzhanova I, Lopes-Pacheco M, Rapino D, et al. Rescuing trafficking mutants of the ATP binding cassette protein, ABCA4, with small molecule correctors as a treatment for Stargardt eye disease. J Biol Chem. 2015;290(32):19743-19755.

29. Sormunen R, Eskelinen S, Lehto VP. Bile canaliculus formation in cultured HEPG2 cells. Lab Invest. 1993;68(6):652-662.

30. Tougeron D, Fotsing G, Barbu V, Beauchant M. ABCB4/ MDR3 gene mutations and Cholangiocarcinomas. J Hepatol. 2012;57(2):467-468.

31. Cosconati S, Forli S, Perryman AL, Harris R, Goodsell DS, Olson AJ. Virtual Screening with AutoDock: Theory and Practice. Expert opinion on drug discovery. 2010;5(6):597607.

32. Gordo-Gilart R, Andueza S, Hierro L, Jara P, Alvarez L. Functional Rescue of TraffickingImpaired ABCB4 Mutants by Chemical Chaperones. PLoS One. 2016;11(2):e0150098.

33. Andress EJ, Nicolaou M, Romero MR, et al. Molecular mechanistic explanation for the spectrum of cholestatic disease caused by the S320F variant of ABCB4. Hepatology. 2014;59(5):1921-1931.

34. Spanò V, Montalbano A, Carbone A, Scudieri P, Galietta LJV, Barraja P. An overview on chemical structures as $\Delta$ F508-CFTR correctors. Eur J Med Chem. 2019;180:430-448.

35. Kinting S, Höppner S, Schindlbeck U, et al. Functional rescue of misfolding ABCA3 mutations by small molecular correctors. Hum Mol Genet. 2018;27(6):943-953.

36. van der Woerd WL, Wichers CG, Vestergaard AL, et al. Rescue of defective ATP8B1 trafficking by CFTR correctors as a therapeutic strategy for familial intrahepatic cholestasis. J Hepatol. 2016;64(6):1339-1347.

37. Carotti M, Marsolier J, Soardi M, et al. Repairing folding-defective $\alpha$-sarcoglycan mutants by CFTR correctors, a potential therapy for limb-girdle muscular dystrophy 2D. Hum Mol Genet. 2018;27(6):969-984. 
38. Wolfhagen FH, Vermeulen HG, de Man RA, Lesterhuis W. Initially obscure hepatotoxicity attributed to sildenafil. European journal of gastroenterology \& hepatology. 2008;20(7):710-712.

39. Enomoto M, Sakaguchi H, Ominami M, et al. Sildenafil-induced severe cholestatic hepatotoxicity. The American journal of gastroenterology. 2009;104(1):254-255.

40. Yoshikado T, Takada T, Yamamoto T, et al. Itraconazole-induced cholestasis: involvement of the inhibition of bile canalicular phospholipid translocator MDR3/ABCB4. Mol Pharmacol. 2011;79(2):241-250.

41. Shi Z, Tiwari AK, Shukla S, et al. Sildenafil reverses ABCB1- and ABCG2-mediated chemotherapeutic drug resistance. Cancer Res. 2011;71(8):3029-3041.

42. Morita SY, Terada T. Molecular mechanisms for biliary phospholipid and drug efflux mediated by ABCB4 and bile salts. Biomed Res Int. 2014;2014:954781.

43. Wang PH, Tu YS, Tseng YJ. PgpRules: a Decision Tree Based Prediction Server for Pglycoprotein Substrates and Inhibitors. Bioinformatics (Oxford, England). 2019;35(20):4193-4195.

44. Ekins S. Drug Transporter Pharmacophores. Transporters as Drug Carriers. 2009(44):215-221.

45. Molinski SV, Shahani VM, Subramanian AS, et al. Comprehensive mapping of cystic fibrosis mutations to CFTR protein identifies mutation clusters and molecular docking predicts corrector binding site. Proteins. 2018;86(8):833-843.

46. Loo TW, Clarke DM. Mapping the Binding Site of the Inhibitor Tariquidar That Stabilizes the First Transmembrane Domain of P-glycoprotein. J Biol Chem. 2015;290(49):2938929401.

47. Degiorgio D, Colombo C, Seia M, et al. Molecular characterization and structural implications of 25 new ABCB4 mutations in progressive familial intrahepatic cholestasis type 3 (PFIC3). Eur J Hum Genet. 2007;15(12):1230-1238.

48. Colombo C, Vajro P, Degiorgio D, et al. Clinical features and genotype-phenotype correlations in children with progressive familial intrahepatic cholestasis type 3 related to ABCB4 mutations. J Pediatr Gastroenterol Nutr. 2011;52(1):73-83.

49. Nakken KE, Labori KJ, Rødningen OK, et al. ABCB4 sequence variations in young adults with cholesterol gallstone disease. Liver Int. 2009;29(5):743-747. 
50. Degiorgio D, Corsetto PA, Rizzo AM, et al. Two ABCB4 point mutations of strategic NBD-motifs do not prevent protein targeting to the plasma membrane but promote MDR3 dysfunction. Eur J Hum Genet. 2014;22(5):633-639.

51. Kim Chiaw P, Wellhauser L, Huan LJ, Ramjeesingh M, Bear CE. A chemical corrector modifies the channel function of F508del-CFTR. Mol Pharmacol. 2010;78(3):411-418. 


\section{FIGURE LEGENDS}

Figure 1. CFTR correctors are not cytotoxic. HEK cells were treated with $10 \mu \mathrm{M}$ of the indicated compounds during 16 hours. Then cytotoxicity was assessed by MTT assay and expressed as the percentage of means for control vehicle-treated cells. Means ( \pm SD) of at least three independent experiments per condition performed in triplicate are shown.

Figure 2. CFTR correctors partially rescue the maturation and the localization of ABCB4I541F. (A) ABCB4-I541F was transiently expressed in HEK cells. After 16 hours of treatment with vehicle (ctrl, control) or $10 \mu \mathrm{M}$ of the indicated compounds, cell lysates were prepared and analysed by immunobloting using the indicated antibodies. ABCB4-WT is shown as reference. The mature and immature forms of ABCB4 are indicated (arrows), as well as molecular weight markers. This panel is representative of at least five independent experiments for each condition. (B) Densitometry analysis of A. The amount of ABCB4-I541F mature form was quantified, normalized to the amount of tubulin, and then expressed as fold change compared to vehicletreated cells (ctrl). Dark grey bars indicate compounds for which means are significantly different from control. Means ( \pm SD) of at least five independent experiments per condition are shown. (C) ABCB4-WT or ABCB4-I541F were expressed in HepG2 cells. After 16 hours of treatment with vehicle (control) or $10 \mu \mathrm{M}$ of the indicated correctors, cells were fixed and permeabilized. Then, after immunolabelling, ABCB4 (red) and endogenous ABCC2 (green) were visualized by confocal microscopy. Nuclei shown in the merged images were labelled with Hoechst 33342 (blue). Asterisks in the lower frames indicate bile canaliculi. This panel is representative of at least three independent experiments per condition. Bars: $10 \mu \mathrm{m}$.

Figure 3. CFTR correctors partially rescue the maturation and the canalicular localization of other ER-retained ABCB4 variants. (A-C) ABCB4-I490T (A), R545H (B) or L556R (C) were transiently expressed in HEK cells. After treatment with $10 \mu \mathrm{M}$ of the indicated CFTR correctors, the maturation of the missense variants was assessed by immunobloting as in Figure 2A. Arrows indicate mature ABCB4. Molecular weight markers (in kDa) are also indicated. These panels are representative of at least five independent experiments for each condition. (D-F) Densitometry analyses of A-C, as performed in Figure 2B. Means ( \pm SD) of at least five independent experiments per condition are represented. (G-I) After treatment with vehicle (control) or $10 \mu \mathrm{M}$ of the indicated CFTR correctors, HepG2 cells expressing ABCB4-I490T (G), 
ABCB4-R545H (H) or ABCB4-L556R (I) were processed for indirect immunofluorescence and confocal microscopy, as described in Figure 2C. Dashed squares indicate magnification shown on the right of each merged panel. Asterisks indicate bile canaliculi. Each panel is representative of at least three independent experiments for each condition. Bars: $10 \mu \mathrm{m}$.

Figure 4. CFTR correctors do not rescue the activity of ER-retained ABCB4 variants and inhibit ABCB4-WT activity. HEK cells expressing ABCB4-I541F (A) ABCB4-I490T (B), ABCB4-R545H (C), ABCB4-L556R (D) or ABCB4-WT (E) were treated with vehicle (ctrl, control) or $10 \mu \mathrm{M}$ of the indicated CFTR correctors, and ABCB4-mediated PC secretion was measured and represented as a percentage of the activity for control vehicle-treated cells expressing ABCB4-WT after background subtraction. Means ( \pm SD) of at least three independent experiments performed in triplicate for each tested condition are shown.

Figure 5. In silico molecular docking of CFTR correctors suggest their direct interaction with ABCB4. (A) In silico molecular docking of the six color-coded CFTR correctors was performed with $\mathrm{ABCB} 4$ in inward-facing $\left(\mathrm{ABCB} 4^{\mathrm{if}}\right)$ and closed conformation $\left(\mathrm{ABCB} 4^{\mathrm{cc}}\right)$ models (see Materials and Methods for details). For ABCB4 ${ }^{\text {if }}$, a single site of potential interaction was identified in the protein chamber while three sites were identified for $\mathrm{ABCB} 4^{\mathrm{cc}}$ in an alternative site and the two ATP-binding sites. For each CFTR corrector and for each site, the 50 poses with the highest affinities from 20 independent simulations are shown. (B) For each of the six CFTR correctors of interest, the contact rate of ABCB4 residues was calculated for the four sites of interest shown in A (see Materials and Methods for details). For the sake of clarity, only residues for which the average contact rates $( \pm \mathrm{SD})$ were higher than the thresholds indicated by the dashed lines are shown.

Figure 6. In silico molecular docking of CFTR correctors reveals putative interaction residues and domains in $\mathbf{A B C B} 4$. (A) $\mathrm{ABCB} 4$ residues indicated in Figure 5B with dark grey bars for which the contact rate is greater than 50\% (ABCB4 $4^{\text {if }}$ - Protein chamber) or $90 \%$ $\left(\mathrm{ABCB} 4^{\mathrm{cc}}\right)$ are represented with their lateral chains in the $3 \mathrm{D}$ structures of $\mathrm{ABCB} 4^{\mathrm{if}}$ and $\mathrm{ABCB} 4^{\mathrm{cc}}$. Each transmembrane domain and nucleotide binding domain are represented in different colors, as well as the coupling helices (see Supplementary Table S6). Underlined residues are further discussed in the Discussion section. (B) ABCB4 transmembrane domains (TM), nucleotide 
binding domains (NBD) and coupling helices $(\mathrm{CH})$, for which potential interaction with CFTR correctors is suggested in Figures 5B and 6A, are highlighted with the indicated color code.

This article is protected by copyright. All rights reserved 


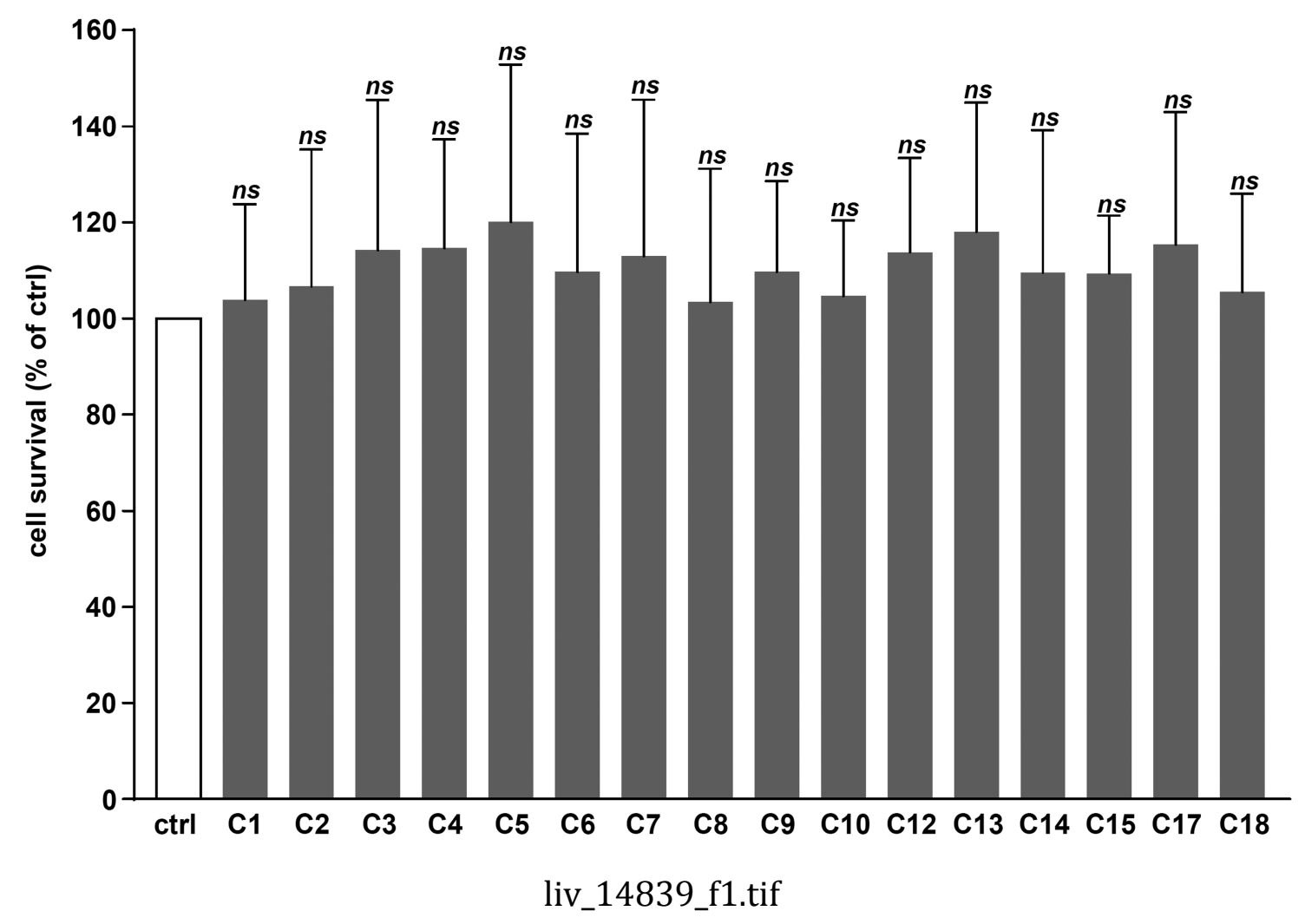

This article is protected by copyright. All rights reserved 

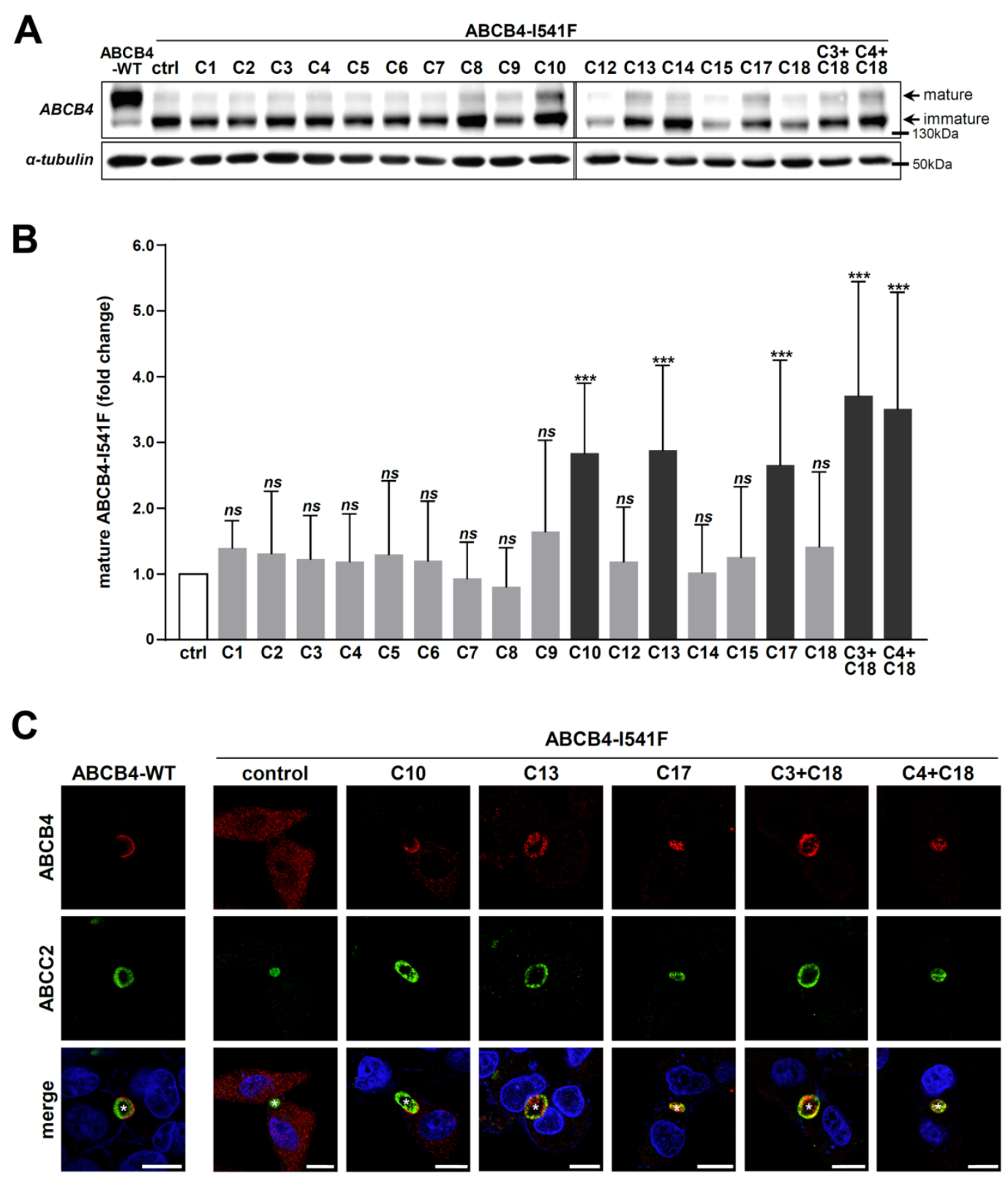

liv_14839_f2.tif 

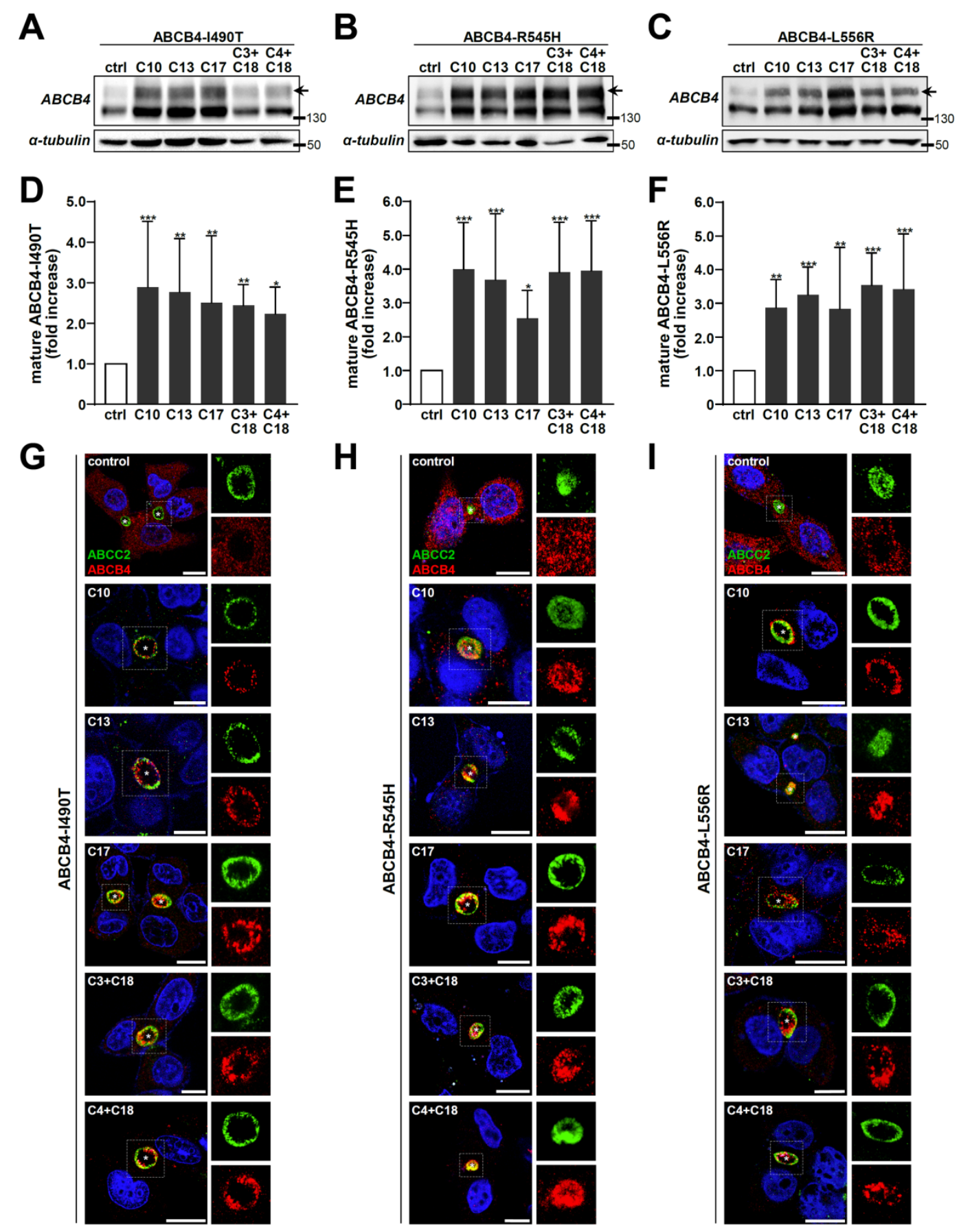

liv_14839_f3.tif 
A

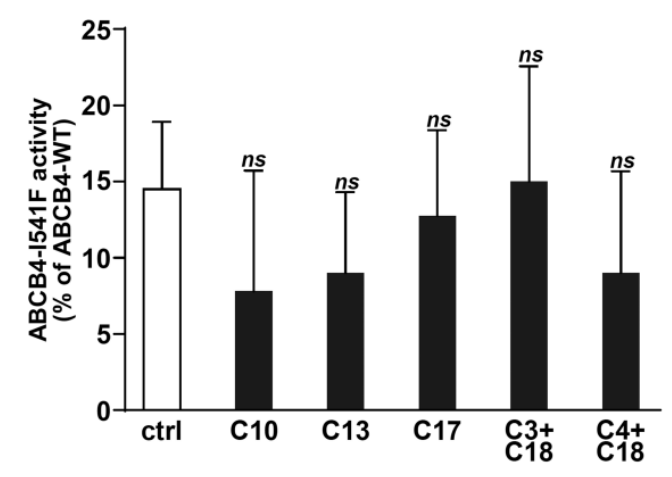

C

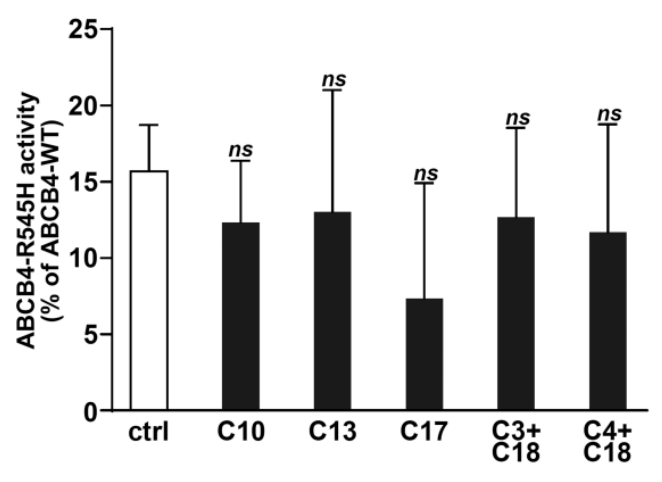

B
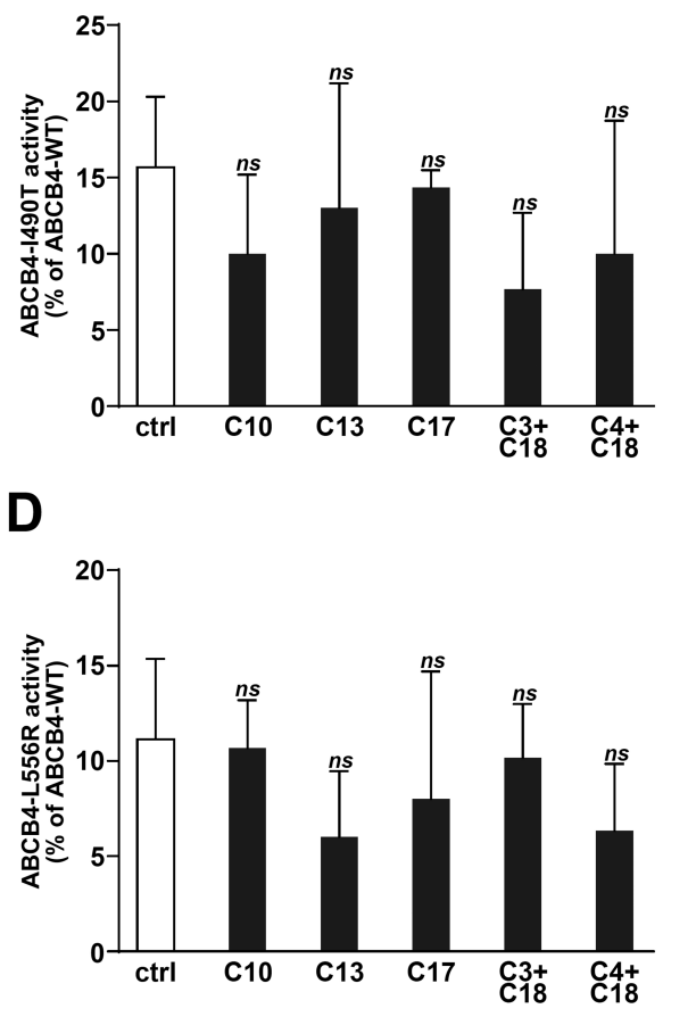

E

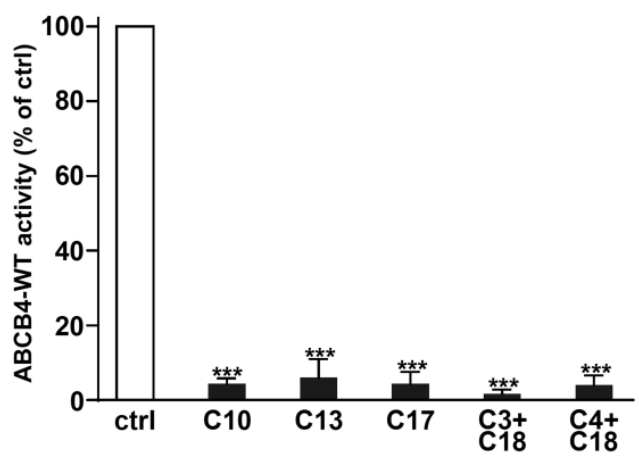

liv_14839_f4.tif 


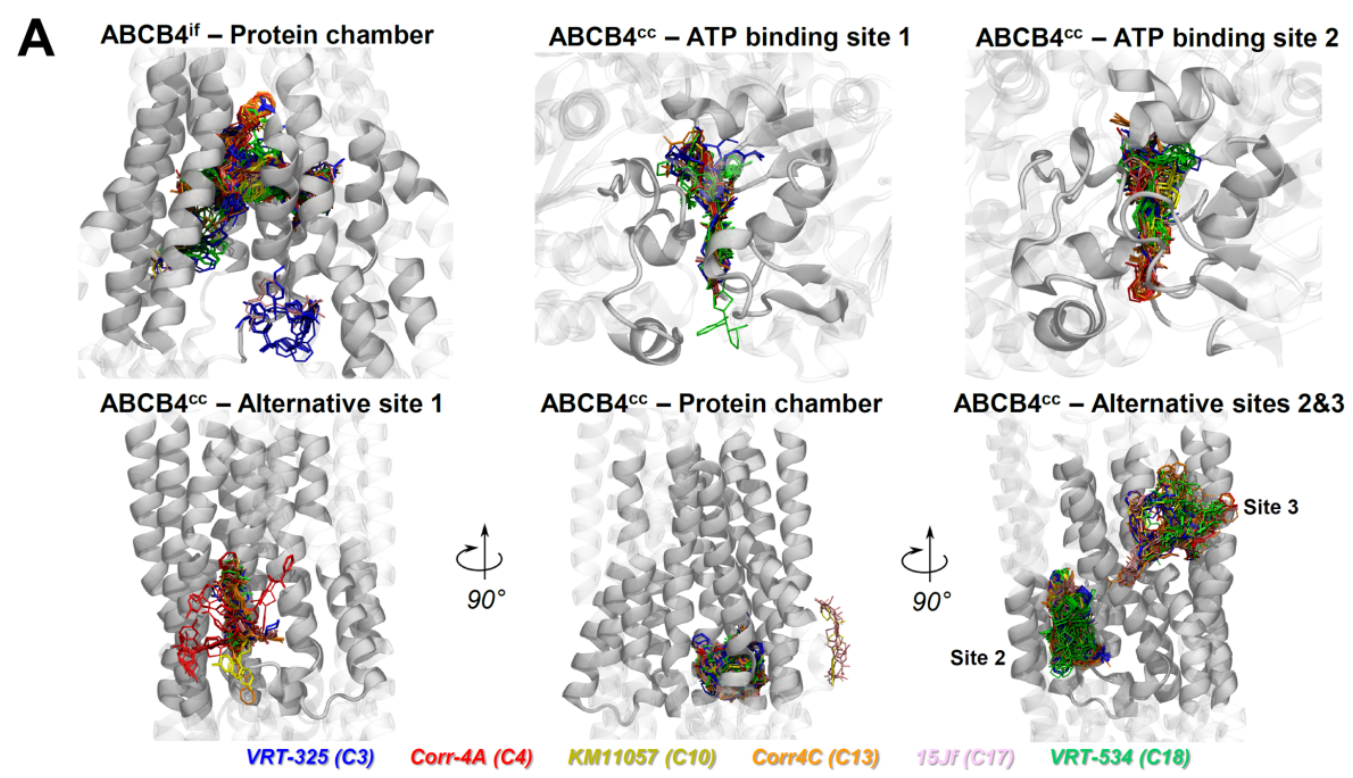

B
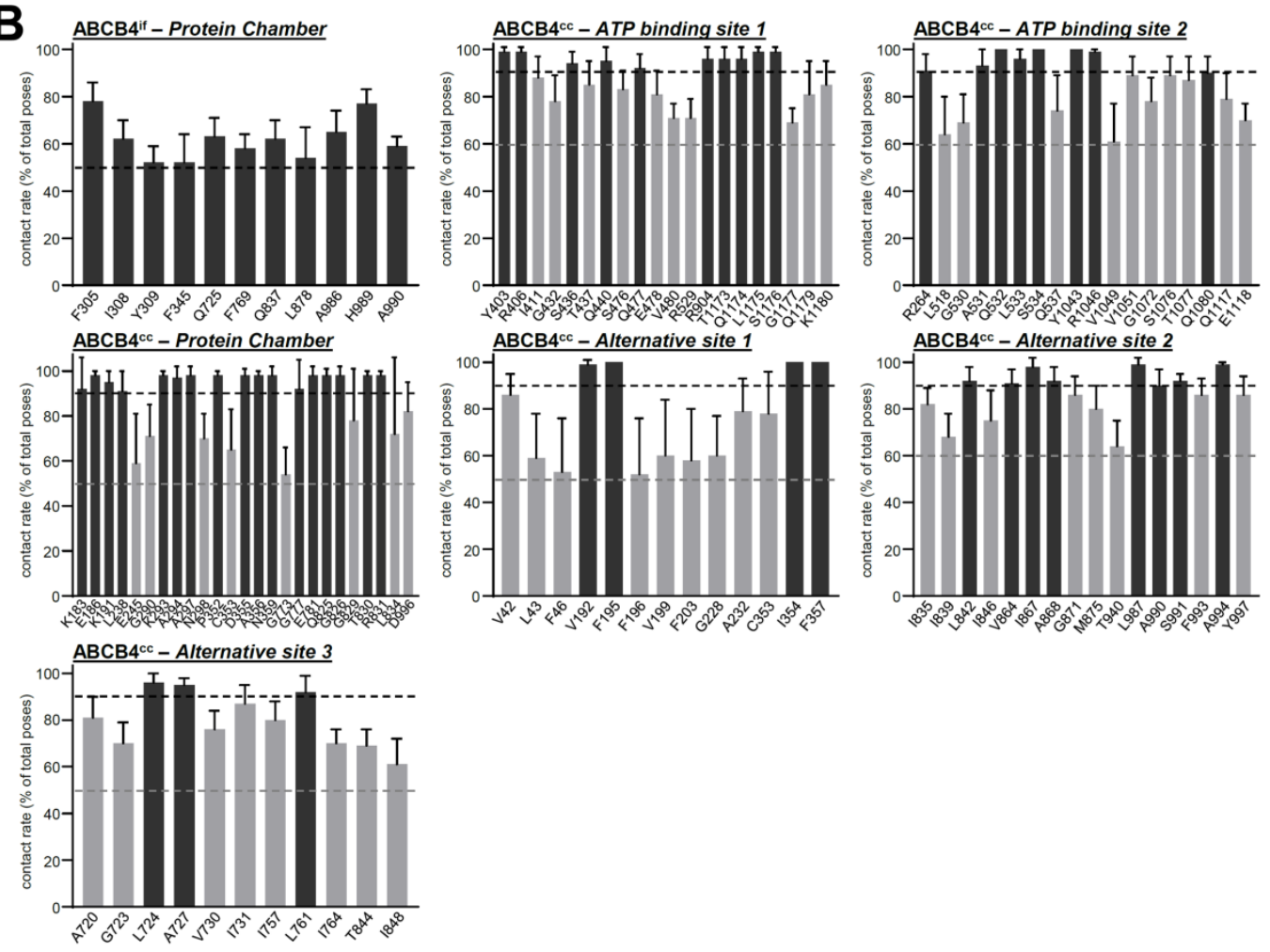

liv_14839_f5.tif

This article is protected by copyright. All rights reserved 

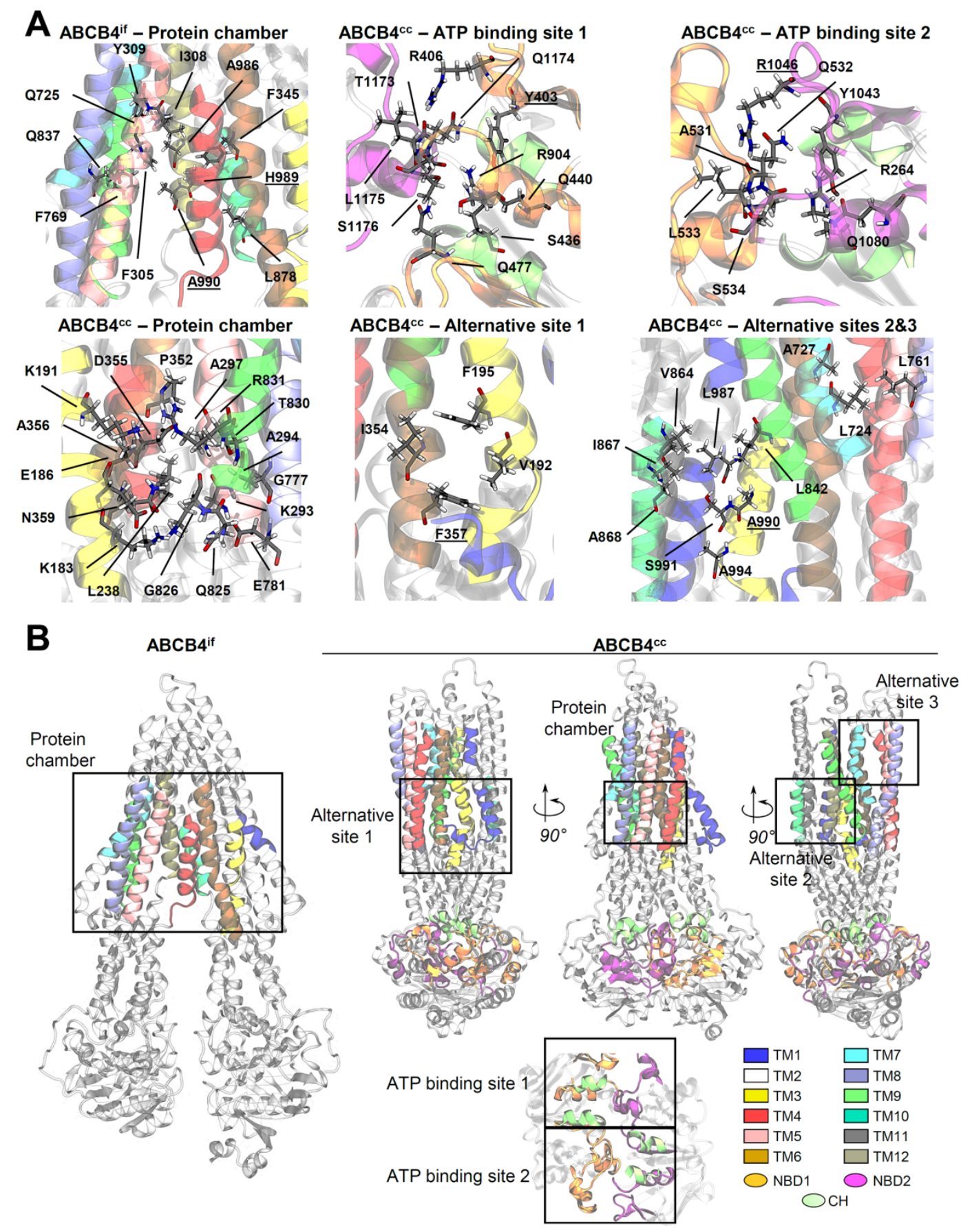

liv_14839_f6.tif

This article is protected by copyright. All rights reserved 


\title{
SUPPLEMENTARY INFORMATION
}

\section{Effect of CFTR correctors on the traffic and the function}

\section{of intracellularly retained $\mathrm{ABCB} 4$ variants}

\author{
Amel Ben Saad ${ }^{1,2}$, Virginie Vauthier ${ }^{2,3}$, Ágota Tóth ${ }^{4}$, Angelika Janaszkiewicz ${ }^{4}$, \\ Anne-Marie Durand-Schneider ${ }^{2}$, Alix Bruneau ${ }^{2,5}$, Jean-Louis Delaunay², \\ Martine Lapalus ${ }^{1}$, Elodie Mareux ${ }^{1}$, Isabelle Garcin ${ }^{1}$, Emmanuel Gonzales ${ }^{1,6}$, \\ Chantal Housset ${ }^{2,7}$, Tounsia Aït-Slimane ${ }^{2}$, Emmanuel Jacquemin ${ }^{1,6}$, Florent Di Meo ${ }^{4}$ \\ Thomas Falguières ${ }^{1, *}$
}

1 Inserm, Université Paris-Saclay, Physiopathogénèse et traitement des maladies du foie, UMR_S 1193, Hepatinov, 91400 Orsay, France.

${ }^{2}$ Inserm, Sorbonne Université, Centre de Recherche Saint-Antoine (CRSA), UMR_S 938, Institute of Cardiometabolism and Nutrition (ICAN), 75012 Paris, France.

3 Current address: Université de Paris, Institut Cochin, Inserm U1016, CNRS UMR 8104, 75014 Paris, France.

${ }^{4}$ Inserm, Université de Limoges, Faculté de Médecine et de Pharmacie, UMR 1248, Campus Marcland, 87000 Limoges, France.

${ }^{5}$ Current address: Department of Hepatology \& Gastroenterology, Charité Universitätsmedizin Berlin, 13353 Berlin, Germany.

${ }^{6}$ Assistance Publique - Hôpitaux de Paris, Paediatric Hepatology \& Paediatric Liver Transplant Department, Reference Center for Rare Paediatric Liver Diseases, FILFOIE, ERN Rare-Liver, Faculté de Médecine Paris-Saclay, CHU Bicêtre, 94270 Le Kremlin-Bicêtre, France.

7 Assistance Publique - Hôpitaux de Paris. Hôpital Saint-Antoine, Reference Center for inflammatory biliary diseases and autoimmune hepatitis, FILFOIE, ERN Rare-Liver, 75012 Paris, France.

*Corresponding author: Thomas Falguières, PhD - UMR_S 1193 Inserm / Université Paris Saclay - Rue des Adèles - Bâtiment 440 - F-91405 Orsay cedex, France. Phone : +33-(0)1-6915-62-94. e-mail: thomas.falguieres@inserm.fr 


\section{SupPlementary Materials ANd Methods}

ABCB4 model preparation. Prior to docking calculations, both models were embedded in water-solvated (3:1) POPC:Cholesterol membrane lipid bilayers using the CHARMM-GUI webserver $^{1-4}$. They were then minimized using the CPU version of PMEMD available in the AMBER18 package, using FF14SB, lipid17 and TIP3P forcefields for protein, lipid and water molecules, respectively ${ }^{5-8}$. Water, ions and lipids were then removed for docking calculations.

Ligands. The whole set of 16 CFTR correctors were initially considered for docking calculations, even though special attention was paid to VRT-325 (C3), Corr-4A (C4), KM1 1057 (C10), Corr-4C (C13), 15Jf (C17) and VRT-534 (C18). Correctors were downloaded from Pubchem (https://pubchem.ncbi.nlm.nih.gov/) ${ }^{9}$ except for C7 which was manually built using the Maestro-Schrödinger Suite 2020-1 software (LLC, New York, NY, 2020). Corrector structures were first minimized at the quantum mechanical level using Density Functional Theory (DFT) M06-2X/6-31+G(d,p) level of theory ${ }^{10}$. Frequency analysis was carried out at the same level of theory to at least ensure a local minimum conformation by checking the absence of imaginary frequency. All relevant dihedral angles were allowed to be flexible during docking calculations (see Supplementary Table S1).

Analysis of non-covalent interactions. Considering the whole set of molecular poses, systematic contact (below $4.5 \AA$ ), H-bond and $\pi$-stacking interaction analyses were performed. H-bond interactions were considered, assuming distance- and angle-cutoffs set up to $3.5 \AA$ and $120^{\circ}$, respectively. Two aromatic rings were considered $\pi$-stacked if: i) the distance between both rings' centers of mass is below $5.0 \AA$; ii) the angle between the two normal vectors to aromatic rings is below $10^{\circ}$. Analyses were carried out and rendered using CPPTRAJ ${ }^{11}$, 
PyTRAJ $19^{12}$ as well as homemade Python3 scripts (available on request) using Numpy20-2 13,14 and Matplotlib22 ${ }^{15}$ packages. 3D and 2D figures were rendered using the VMD 1.9.3 ${ }^{16}$ and CS ChemDraw softwares, respectively. 
Supplementary Table S1. Chemical structures of CFTR correctors used in this study

\begin{tabular}{|c|c|c|c|c|c|c|}
\hline Compound & IUPAC name & $\begin{array}{l}\text { Alternative } \\
\text { name }\end{array}$ & Chemical Structure & $\begin{array}{l}\text { PubChem } \\
\text { CID }\end{array}$ & $\begin{array}{l}\text { MW } \\
\text { (Da) }\end{array}$ & References \\
\hline $\mathrm{C} 1$ & $\begin{array}{c}\text { 6-(1H-Benzoimidazol-2- } \\
\text { ylsulfanylmethyl)-2-(6-methoxy-4- } \\
\text { methyl-quinazolin-2-ylamino)- } \\
\text { pyrimidin-4-ol }\end{array}$ & Corr-3a & & $\underline{135486495}$ & 445.5 & 17 \\
\hline $\mathrm{C} 2$ & $\begin{array}{c}\text { 2-(1- }\{4-[(4-C h l o r o p h e n y l) \text { sulfonyl]- } \\
\text { 1-piperazinyl }\} \text { ethyl })-4-(1- \\
\text { piperidinyl)quinazoline }\end{array}$ & VRT-640 & & $\underline{23632303}$ & 500.1 & 18 \\
\hline $\mathrm{C} 3$ & $\begin{array}{l}\text { 4-(Cyclohexyloxy)-2-(1-(4-[(4- } \\
\text { methoxybenzene)sulfonyl]piperazin- } \\
\text { 1-yl)ethyl)quinazoline }\end{array}$ & VRT-325 & & $\underline{11957831}$ & 510.6 & 19 \\
\hline $\mathrm{C} 4$ & $\begin{array}{c}\mathrm{N}-(2-(5-\text {-Chloro-2- } \\
\text { methoxyphenylamino)-4'-methyl- } \\
\text { 4,5'-bithiazol-2'-yl)benzamide }\end{array}$ & Corr-4a & & $\underline{1144671}$ & 457.0 & 17 \\
\hline $\mathrm{C} 5$ & $\begin{array}{c}\text { 4,5,7-trimethyl-N-phenylquinolin-2- } \\
\text { amine }\end{array}$ & Corr-5a & & $\underline{740918}$ & 262.3 & 17 \\
\hline C6 & $\begin{array}{l}\mathrm{N} \text {-(4-bromophenyl)-4- } \\
\text { methylquinolin-2-amine }\end{array}$ & Corr-5c & & $\underline{768745}$ & 313.2 & 17 \\
\hline $\mathrm{C} 7$ & $\begin{array}{l}\text { 2-(4-isopropoxypicolinoyl)-N-(4- } \\
\text { pentylphenyl)-1,2,3,4- } \\
\text { tetrahydroisoquinoline-3- } \\
\text { carboxamide }\end{array}$ & $\begin{array}{l}\text { Compound } \\
\quad 48\end{array}$ & & not applicable & 485.6 & 20 \\
\hline $\mathrm{C} 8$ & $\begin{array}{l}\text { N-(2-fluorophenyl)-2-(1H-indol-3- } \\
\text { yl)-2-oxoacetamide }\end{array}$ & $\begin{array}{c}\text { not } \\
\text { applicable }\end{array}$ & & $\underline{2986288}$ & 282.3 & 18 \\
\hline C9 & $\begin{array}{l}\text { 7-Chloro-4-[4-(4- } \\
\text { chlorophenyl)sulfonylpiperazin-1- } \\
\text { yl]quinoline }\end{array}$ & KM11060 & & $\underline{1241327}$ & 422.3 & 21 \\
\hline $\mathrm{C} 10$ & $\begin{array}{l}\text { 7-Chloro-4-[4- } \\
\text { (phenylsulfonyl)piperazin-1- } \\
\text { yl]quinoline }\end{array}$ & KM11057 & & $\underline{1241326}$ & 387.9 & 21 \\
\hline $\mathrm{C} 12$ & $\begin{array}{l}\text { N-(4-Fluorophenyl)-4-(4- } \\
\text { methylphenyl)-1,3-thiazol-2-amine }\end{array}$ & Corr- $2 \mathrm{i}$ & & $\underline{625111}$ & 284.4 & 17 \\
\hline $\mathrm{C} 13$ & $\begin{array}{l}\text { N-[2-(3-Acetyl-phenylamino)-4'- } \\
\text { methyl-[4,5']bithiazolyl-2'-yl]- } \\
\text { benzamide }\end{array}$ & Corr-4c & & $\underline{2230879}$ & 434.5 & 17 \\
\hline $\mathrm{C} 14$ & $\begin{array}{l}\text { N-[2-(2-Methoxy-phenylamino)-4'- } \\
\text { methyl-[4,5']bithiazolyl-2'-yl]- } \\
\text { benzamide }\end{array}$ & Corr- $4 \mathrm{~d}$ & & $\underline{1117191}$ & 422.5 & 17 \\
\hline $\mathrm{C} 15$ & $\begin{array}{l}\text { Phenyl-[4-(4-vinyl-phenyl)-thiazol- } \\
\text { 2-yl]-amine }\end{array}$ & Corr- $2 b$ & & $\underline{683025}$ & 278.4 & 17 \\
\hline $\mathrm{C} 17$ & $\begin{array}{c}\mathrm{N}-[5-[2-(5-C h l o r o-2- \\
\text { methoxyanilino)-1,3-thiazol-4-yl]-4- } \\
\text { methyl-1,3-thiazol-2-yl]-2,2- } \\
\text { dimethylpropanamide }\end{array}$ & $\begin{array}{l}\text { Compound } \\
15 \mathrm{Jf}\end{array}$ & & $\underline{11958611}$ & 437.0 & 22 \\
\hline $\mathrm{C} 18$ & $\begin{array}{l}\text { 1-(1,3-Benzodioxol-5-yl)-N-[5-[(S)- } \\
\text { (2-chlorophenyl)-[(2R)-2- } \\
\text { hydroxypyrrolidin-1-yl]methyl]-1,3- } \\
\text { thiazol-2-yl]cyclopropane-1- } \\
\text { carboxamide }\end{array}$ & VRT-534 & & $\underline{86621212}$ & 498.0 & 18 \\
\hline
\end{tabular}


Supplementary Table S2. Technical parameters of blind and refined molecular docking calculations.

(A) Box parameter coordinates (center and size)

\begin{tabular}{|c|c|c|c|c|c|c|c|c|c|}
\hline \multirow{2}{*}{ Structure } & \multirow{2}{*}{ Modelled sequence } & \multirow{2}{*}{ Docking calculation } & \multirow{2}{*}{ Volume search space } & \multicolumn{3}{|c|}{ Box center } & \multicolumn{3}{|c|}{ Box size } \\
\hline & & & & $x$ & $y$ & $z$ & $x$ & $y$ & $z$ \\
\hline \multirow[t]{3}{*}{$\mathrm{ABCB} 4^{\mathrm{if}}$} & $42-629$ & Blind & Overall & 61.6 & 60.6 & 59.4 & 80.0 & 65.0 & 120.0 \\
\hline & $692-1251$ & Refined & Protein chamber A & 60.0 & 62.7 & 94.4 & 29.5 & 29.5 & 29.5 \\
\hline & & & Protein chamber B & 69.0 & 53.0 & 83.0 & 26.0 & 20.0 & 30.0 \\
\hline \multirow[t]{7}{*}{$\mathrm{ABCB} 4^{\mathrm{cc}}$} & $42-629$ & Blind & Overall & 60.5 & 62.1 & 67.2 & 80.0 & 65.0 & 120.0 \\
\hline & $692-1251$ & Refined & Protein chamber & 68.0 & 73.0 & 79.0 & 20.0 & 20.0 & 20.0 \\
\hline & & & Alternative site 1 & 51.1 & 72.9 & 80.0 & 23.0 & 23.0 & 23.0 \\
\hline & & & Alternative site 2 & 66.0 & 52.0 & 84.0 & 20.0 & 20.0 & 20.0 \\
\hline & & & Alternative site 3 & 68.0 & 69.0 & 100.0 & 26.0 & 28.0 & 20.0 \\
\hline & & & ATP-binding site 1 & 52.7 & 70.3 & 31.5 & 23.0 & 28.0 & 23.0 \\
\hline & & & ATP-binding site 2 & 65.2 & 49.3 & 30.7 & 23.0 & 28.0 & 23.0 \\
\hline
\end{tabular}

(B) Flexible residues in each volume search space.

\begin{tabular}{|c|c|c|c|}
\hline Structure & Docking calculation & Volume search space & Flexible residues \\
\hline \multirow[t]{3}{*}{$\mathrm{ABCB} 4^{\text {if }}$} & Blind & Overall & None \\
\hline & Refined & Protein chamber A & $\begin{array}{l}234,305,309,311,312,337,338,339,345,346,349,725,728,729 \text {, } \\
841,870,874,944,952,978,982,989\end{array}$ \\
\hline & & Protein chamber B & $\begin{array}{l}191,195,196,201,224,236,239,242,243,345,346,349,355,357, \\
359\end{array}$ \\
\hline \multirow[t]{7}{*}{$\mathrm{ABCB} 4^{\mathrm{cc}}$} & Blind & Overall & None \\
\hline & Refined & Protein chamber & $\begin{array}{l}234,296,298,300,349,355,766,767,768,769,770,772,774,778, \\
830,837\end{array}$ \\
\hline & & Alternative site 1 & $44,46,195,196,239,357$ \\
\hline & & Alternative site 2 & $838,870,874,937,940,941,944,945,991,992,993$ \\
\hline & & Alternative site 3 & $\begin{array}{l}309,311,312,316,338,345,725,728,768,769,770,772,774,778 \\
830,837\end{array}$ \\
\hline & & ATP-binding site 1 & $\begin{array}{l}166,402,403,405,435,436,437,438,440,476,477,478,557,558 \\
902,905,908,1156,1166,1173,1174,1176,1179,1180\end{array}$ \\
\hline & & ATP-binding site 2 & $\begin{array}{l}513,514,517,524,532,534,537,538,1042,1043,1045,1053,1071, \\
1076,1077,1080,1116,1117,1118,1199,1200\end{array}$ \\
\hline
\end{tabular}


Supplementary Table S3. Spatial distributions of the whole set of CFTR correctors over defined binding sites and out of these zones originally obtained from blind molecular docking calculations.

\begin{tabular}{|c|c|c|c|c|c|c|}
\hline \multirow{2}{*}{$\begin{array}{c}\text { CFTR } \\
\text { Correctors }\end{array}$} & \multicolumn{2}{|c|}{$\mathrm{ABCB} 4^{\mathrm{if}}$} & \multicolumn{4}{|c|}{$\mathrm{ABCB} 4^{\mathrm{cc}}$} \\
\hline & $\begin{array}{c}\text { Protein } \\
\text { chamber A }\end{array}$ & $\begin{array}{l}\text { Out of } \\
\text { zone }\end{array}$ & Alternative site 1 & ATP-binding site 1 & ATP-binding site 2 & Out of zone \\
\hline $\mathrm{C} 1$ & 0.98 & 0.02 & 0.02 & 0.28 & 0.46 & 0.24 \\
\hline $\mathrm{C} 2$ & 0.89 & 0.11 & 0.56 & 0.05 & 0.16 & 0.23 \\
\hline $\mathrm{C} 3$ & 0.90 & 0.10 & 0.52 & 0.07 & 0.18 & 0.24 \\
\hline $\mathrm{C} 4$ & 1.00 & 0.01 & 0.29 & 0.16 & 0.50 & 0.06 \\
\hline $\mathrm{C} 5$ & 0.94 & 0.07 & 0.25 & 0.18 & 0.40 & 0.17 \\
\hline $\mathrm{C} 6$ & 0.91 & 0.10 & 0.33 & 0.18 & 0.32 & 0.17 \\
\hline $\mathrm{C} 7$ & 1.00 & 0.00 & 0.43 & 0.06 & 0.11 & 0.40 \\
\hline $\mathrm{C} 8$ & 0.95 & 0.05 & 0.04 & 0.20 & 0.34 & 0.42 \\
\hline C9 & 0.92 & 0.08 & 0.26 & 0.12 & 0.44 & 0.18 \\
\hline $\mathrm{C10}$ & 0.90 & 0.10 & 0.35 & 0.12 & 0.41 & 0.13 \\
\hline $\mathrm{C} 12$ & 0.95 & 0.05 & 0.32 & 0.21 & 0.41 & 0.07 \\
\hline C13 & 0.99 & 0.01 & 0.24 & 0.24 & 0.52 & 0.01 \\
\hline C14 & 0.96 & 0.04 & 0.26 & 0.16 & 0.53 & 0.05 \\
\hline $\mathrm{C} 15$ & 0.97 & 0.03 & 0.36 & 0.17 & 0.37 & 0.11 \\
\hline $\mathrm{C} 17$ & 0.98 & 0.02 & 0.17 & 0.16 & 0.46 & 0.22 \\
\hline C18 & 0.92 & 0.08 & 0.44 & 0.04 & 0.16 & 0.36 \\
\hline $\begin{array}{l}\text { Average } \\
\text { (Overall) }\end{array}$ & $0.95 \pm 0.04$ & $\begin{array}{c}0.05 \pm \\
0.04\end{array}$ & $0.30 \pm 0.15$ & $0.15 \pm 0.07$ & $0.36 \pm 0.14$ & $0.19 \pm 0.12$ \\
\hline $\begin{array}{l}\text { Average } \\
\text { (Selected) }\end{array}$ & $0.95 \pm 0.05$ & $\begin{array}{c}0.05 \pm \\
0.04\end{array}$ & $0.34 \pm 0.13$ & $0.13 \pm 0.07$ & $0.37 \pm 0.16$ & $0.17 \pm 0.13$ \\
\hline
\end{tabular}


Supplementary Table S4. Minimum and maximum affinity energies $\left(\Delta \mathrm{G}_{\min }\right.$ and $\Delta \mathrm{G}_{\max }$, respectively; in $\mathrm{kcal}^{\mathrm{mol}} \mathrm{m}^{-1}$ ) obtained from refined molecular docking calculations on $\mathrm{ABCB} 4^{\text {if }}(\mathrm{A})$ and $\mathrm{ABCB} 4^{\mathrm{cc}}(\mathrm{B})$, as well as minimum docking affinity mean signed deviation (MSD, kcal.mol ${ }^{-1}$ ) with respect to Protein chamber A and ATP-binding site 1 for $\mathrm{ABCB} 44^{\text {if }}$ and $\mathrm{ABCB} 4^{\mathrm{cc}}$, respectively.

\section{(A)}

\begin{tabular}{|c|c|c|c|c|c|c|}
\hline & \multicolumn{3}{|c|}{ Protein chamber A } & \multicolumn{3}{|c|}{ Protein chamber B } \\
\hline & $\Delta \mathrm{G}_{\min }$ & $\Delta \mathrm{G}_{\max }$ & \# & $\Delta \mathrm{G}_{\min }$ & $\Delta \mathrm{G}_{\max }$ & \# \\
\hline $\mathrm{C} 1$ & -10.7 & -9.1 & 399 & -10.0 & -6.5 & 263 \\
\hline $\mathrm{C} 2$ & -10.3 & -8.9 & 400 & -10.5 & 1.4 & 135 \\
\hline $\mathbf{C 3}$ & -10.3 & -8.9 & 400 & -10.4 & -5.2 & 177 \\
\hline $\mathrm{C} 4$ & -9.6 & -8.2 & 398 & -9.6 & -6.7 & 177 \\
\hline $\mathrm{C} 5$ & -9.6 & -7.3 & 379 & -8.7 & -0.1 & 330 \\
\hline C6 & -9.3 & -6.9 & 398 & -8.0 & -5.7 & 343 \\
\hline $\mathrm{C} 7$ & -12.2 & -8.5 & 278 & -9.3 & -1.2 & 254 \\
\hline $\mathrm{C} 8$ & -9.5 & -7.2 & 383 & -8.0 & -6.1 & 400 \\
\hline C9 & -9.9 & -7.8 & 397 & -9.7 & -6.1 & 131 \\
\hline C10 & -9.7 & -7.6 & 400 & -9.3 & -5.3 & 219 \\
\hline $\mathrm{C} 12$ & -8.9 & -7.3 & 400 & -8.1 & -3.8 & 362 \\
\hline C13 & -10.3 & 2.3 & 399 & -10.2 & 3.5 & 158 \\
\hline C14 & -9.8 & -7.9 & 398 & -9.5 & 1.7 & 180 \\
\hline $\mathrm{C} 15$ & -8.8 & -7.1 & 397 & -8.0 & -5.6 & 375 \\
\hline C17 & -8.9 & -7.3 & 399 & -8.1 & -5.9 & 377 \\
\hline C18 & -10.5 & -8.8 & 400 & -10.1 & -4.8 & 300 \\
\hline MSD & \multicolumn{3}{|c|}{ - } & \multicolumn{3}{|c|}{$0.7 \pm 0.8$} \\
\hline
\end{tabular}

\# indicates the selected number of poses for each molecule, with a maximum $2 \mathrm{kcal}^{\mathrm{m} m \mathrm{l}^{-1}}$ range with respect to the top-ranked pose for each ABCB4 state/CFTR corrector/region triad. Selected CFTR correctors are shown in bold. 
(B)

\begin{tabular}{|c|c|c|c|c|c|c|c|c|c|c|c|c|c|c|c|c|c|c|}
\hline & \multicolumn{3}{|c|}{ Protein chamber } & \multicolumn{3}{|c|}{ Alternative site 1} & \multicolumn{3}{|c|}{ Alternative site 2} & \multicolumn{3}{|c|}{ Alternative site 3} & \multicolumn{3}{|c|}{ ATP binding site 1} & \multicolumn{3}{|c|}{ ATP binding site 2} \\
\hline & $\Delta \mathrm{G}_{\min }$ & $\Delta \mathrm{G}_{\max }$ & \# & $\Delta \mathrm{G}_{\min }$ & $\Delta \mathrm{G}_{\max }$ & \# & $\Delta \mathrm{G}_{\min }$ & $\Delta \mathrm{G}_{\max }$ & \# & $\Delta \mathrm{G}_{\min }$ & $\Delta \mathrm{G}_{\max }$ & $\#$ & $\Delta \mathrm{G}_{\min }$ & $\Delta \mathrm{G}_{\max }$ & \# & $\Delta \mathrm{G}_{\min }$ & $\Delta \mathrm{G}_{\max }$ & \# \\
\hline $\mathrm{C} 1$ & -9.2 & 5.9 & 69 & -9.7 & -8.1 & 399 & -9.8 & -0.5 & 223 & -7.1 & -5.9 & 400 & -11.6 & -9.0 & 365 & -11.1 & -8.8 & 385 \\
\hline $\mathrm{C} 2$ & -5.2 & 8.1 & 61 & -10.2 & -8.9 & 393 & -9.6 & 3.9 & 321 & -7.1 & -6.0 & 400 & -11.4 & -7.5 & 175 & -12.4 & -8.7 & 138 \\
\hline $\mathbf{C 3}$ & -7.4 & 8.8 & 46 & -10.4 & -8.5 & 400 & -9.3 & 0.7 & 386 & -7.2 & -6.4 & 400 & -12.1 & -7.8 & 111 & -11.9 & -8.8 & 219 \\
\hline $\mathrm{C} 4$ & -6.7 & 7.4 & 112 & -8.8 & -5.5 & 396 & -8.3 & 6.6 & 334 & -6.9 & -0.4 & 398 & -9.9 & -7.4 & 372 & -10.3 & -7.4 & 327 \\
\hline $\mathrm{C} 5$ & -8.7 & 6.7 & 111 & -10.0 & -7.1 & 207 & -7.5 & 7.1 & 363 & -6.3 & -5.0 & 400 & -9.3 & -6.2 & 358 & -9.5 & -6.1 & 259 \\
\hline $\mathrm{C} 6$ & -7.5 & 7.7 & 91 & -9.2 & -6.6 & 280 & -7.2 & 5.3 & 329 & -6.1 & -4.1 & 399 & -9.0 & -6.3 & 307 & -9.0 & -5.5 & 342 \\
\hline C7 & -8.1 & 3.6 & 57 & -9.7 & -7.8 & 397 & -8.1 & 5.7 & 389 & -7.1 & -5.9 & 400 & -9.9 & -3.1 & 111 & -11.6 & -5.8 & 249 \\
\hline $\mathrm{C} 8$ & -8.7 & 5.9 & 213 & -8.5 & -6.7 & 398 & -7.4 & 2.2 & 388 & -6.0 & -2.8 & 398 & -9.3 & -7.5 & 397 & -9.6 & -7.0 & 327 \\
\hline C9 & -7.0 & 8.1 & 36 & -9.0 & -7.3 & 400 & -8.1 & 4.3 & 258 & -6.4 & -5.6 & 400 & -10.2 & -5.9 & 248 & -10.7 & -7.6 & 289 \\
\hline C10 & -7.7 & 8.7 & 33 & -9.3 & -7.0 & 352 & -7.9 & 4.3 & 255 & -6.5 & -5.2 & 399 & -9.8 & -6.8 & 267 & -10.5 & -7.5 & 310 \\
\hline $\mathrm{C} 12$ & -7.6 & 7.8 & 96 & -9.1 & -7.2 & 398 & -8.0 & 6.6 & 193 & -6.1 & -4.3 & 399 & -8.7 & -6.7 & 388 & -9.2 & -6.3 & 315 \\
\hline C13 & -7.9 & 7.0 & 104 & -10.1 & -8.6 & 400 & -8.7 & 2.6 & 327 & -7.3 & -6.2 & 400 & -10.2 & -7.4 & 359 & -10.7 & -3.5 & 304 \\
\hline C14 & -7.9 & 5.6 & 132 & -9.1 & -4.2 & 397 & -8.3 & 1.5 & 277 & -6.6 & -5.6 & 399 & -9.9 & -7.1 & 325 & -10.0 & -6.6 & 324 \\
\hline C15 & -7.4 & 8.2 & 106 & -8.6 & -6.6 & 391 & -7.6 & 7.1 & 252 & -6.0 & -4.3 & 400 & -8.4 & -6.3 & 386 & -9.3 & -5.6 & 255 \\
\hline C17 & -5.4 & 8.8 & 127 & -8.5 & -6.5 & 392 & -7.4 & 3.8 & 385 & -6.5 & -5.2 & 400 & -9.2 & -6.6 & 327 & -9.4 & -6.8 & 368 \\
\hline C18 & -7.5 & 6.7 & 119 & -9.8 & -7.3 & 264 & -9.3 & 1.2 & 380 & -6.4 & -5.6 & 400 & -11.0 & -2.0 & 336 & -10.1 & -7.4 & 192 \\
\hline MSD & \multicolumn{3}{|c|}{$2.5 \pm 1.5$} & \multicolumn{3}{|c|}{$0.6 \pm 0.8$} & \multicolumn{3}{|c|}{$1.7 \pm 0.5$} & \multicolumn{3}{|c|}{$3.4 \pm 0.8$} & \multicolumn{3}{|c|}{-} & \multicolumn{3}{|c|}{$-0.3 \pm 0.6$} \\
\hline
\end{tabular}

\# indicates the selected number of poses for each molecule, with a maximum $2 \mathrm{kcal}^{-m o l^{-1}}$ range with respect to the top-ranked pose for each ABCB4 state/CFTR corrector/region triad. Selected CFTR correctors are shown in bold 
Supplementary Table S5. Description of non-covalent interactions of CFTR correctors with $\mathrm{ABCB} 44^{\text {if }}$ and $\mathrm{ABCB} 4^{\mathrm{cc}}$.

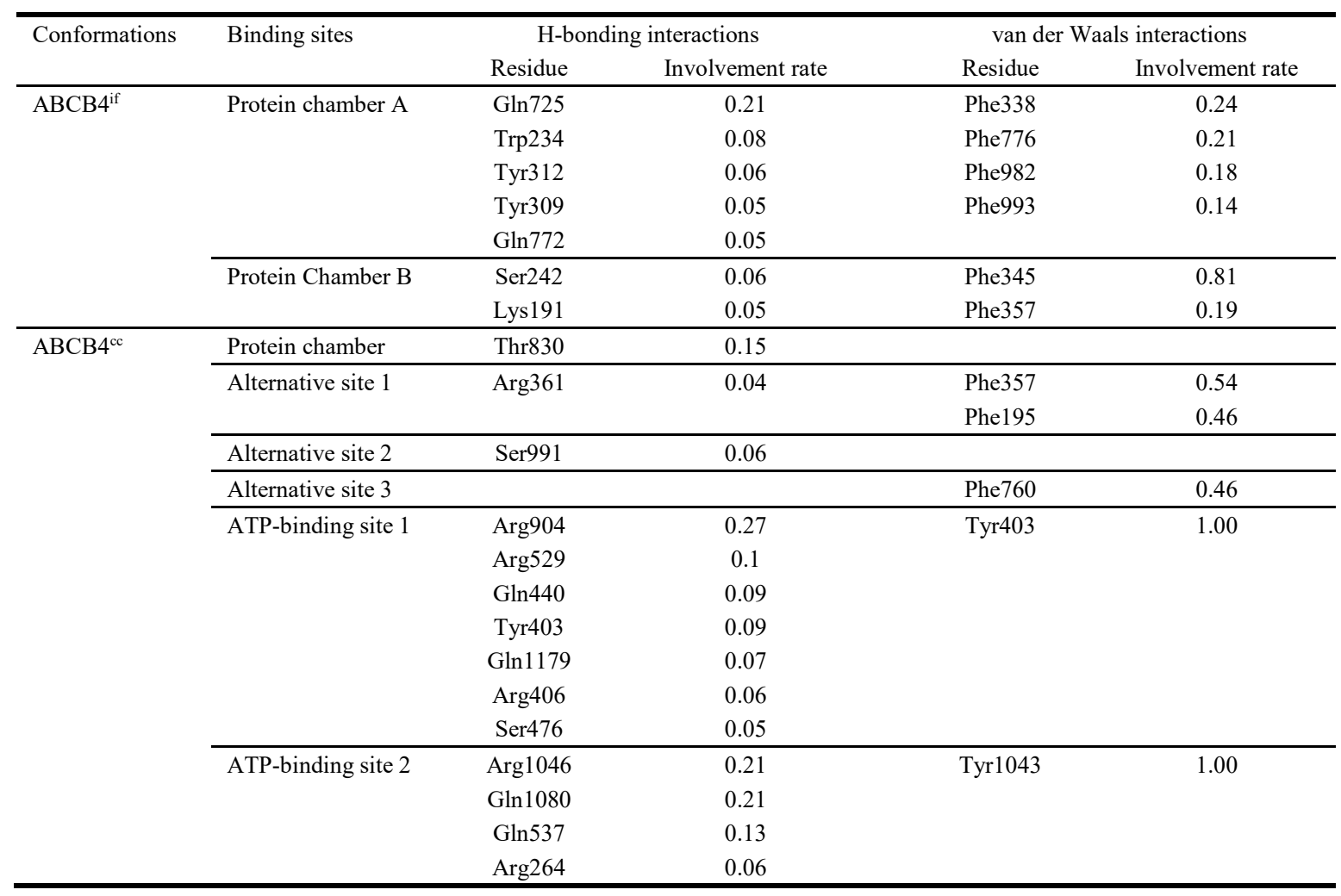


Supplementary Table S6. Sequence-based definitions of $\mathrm{ABCB} 4^{\text {if }}(\mathrm{A})$ and $\mathrm{ABCB} 4^{\mathrm{cc}}(\mathrm{B})$ binding sites from molecular docking calculations. Locations according to transmembrane helices (TM), nucleotide binding domains (NBD) and coupling helices $(\mathrm{CH})$ are reported.

(A)

\begin{tabular}{cccc}
\hline & Protein Chamber A & Protein Chamber B & Color code in Figure 6A-B \\
\hline TM1 & - & $63-70$ & \\
TM2 & - & $137-143$ & \\
TM3 & - & $183-203$ & \\
TM4 & $227-240$ & $223-243$ & \\
TM5 & $291-314$ & $307-309$ & \\
TM6 & $336-353$ & $341-362$ & \\
NBD1 & - & - & \\
TM7 & $717-731$ & - & \\
TM8 & $756-780$ & - \\
TM9 & $828-846$ & - & \\
TM10 & $867-878$ & $877-880$ & \\
TM11 & - & - \\
TM12 & $975-993$ & - \\
NBD2 & - & - \\
CH2-3 & - & - \\
CH4-5 & - & - & \\
CH8-9 & - & - & \\
CH10-11 & - & & \\
\hline
\end{tabular}


(B)

\begin{tabular}{|c|c|c|c|c|c|c|c|}
\hline & $\begin{array}{c}\text { Protein } \\
\text { Chamber }\end{array}$ & $\begin{array}{c}\text { Alternative } \\
\text { site } 1\end{array}$ & $\begin{array}{l}\text { Alternative } \\
\text { site } 2 \\
\end{array}$ & $\begin{array}{c}\text { Alternative } \\
\text { site } 3\end{array}$ & $\begin{array}{c}\text { ATP-binding } \\
\text { site } 1\end{array}$ & $\begin{array}{c}\text { ATP-binding } \\
\text { site } 2\end{array}$ & $\begin{array}{c}\text { Color code } \\
\text { in Figure } 6 \mathrm{~A}-\mathrm{B}\end{array}$ \\
\hline TM1 & - & $42-65$ & - & $71-79$ & - & - & \\
\hline TM2 & - & - & - & - & - & - & \\
\hline TM3 & - & $185-200$ & - & - & - & - & \\
\hline TM4 & $230-239$ & $225-241$ & - & $216-225$ & - & - & \\
\hline TM5 & 291-305 & & - & $305-320$ & - & - & \\
\hline TM6 & $347-360$ & $346-361$ & - & $334-347$ & - & - & \\
\hline NBD1 & - & - & - & - & $\begin{array}{c}401-415, \\
431-446 \\
474-481 \\
555-561\end{array}$ & $\begin{array}{c}479-485,510-539 \\
561-563\end{array}$ & \\
\hline TM7 & 714-719 & - & - & $720-734$ & - & - & \\
\hline TM8 & 766-781 & - & - & $752-766$ & - & - & \\
\hline TM9 & $828-838$ & - & $835-844$ & $840-853$ & - & - & \\
\hline TM10 & - & - & $864-877$ & - & - & - & \\
\hline TM11 & - & - & $937-947$ & - & - & - & \\
\hline TM12 & - & - & 984-996 & $973-986$ & - & - & \\
\hline NBD2 & - & - & - & - & $\begin{array}{l}1118-1123 \\
1155-1181 \\
1203-1204\end{array}$ & $\begin{array}{l}1041-1053, \\
1071-1085, \\
1115-1118, \\
1197-1203, \\
1247-1248\end{array}$ & \\
\hline $\mathrm{CH} 2-3$ & - & - & - & - & $161-167$ & - & \\
\hline $\mathrm{CH} 4-5$ & - & - & - & - & - & $262-268$ & \\
\hline CH8-9 & - & - & - & - & - & 799-804 & \\
\hline CH10-11 & - & - & - & - & 901-909 & & \\
\hline
\end{tabular}




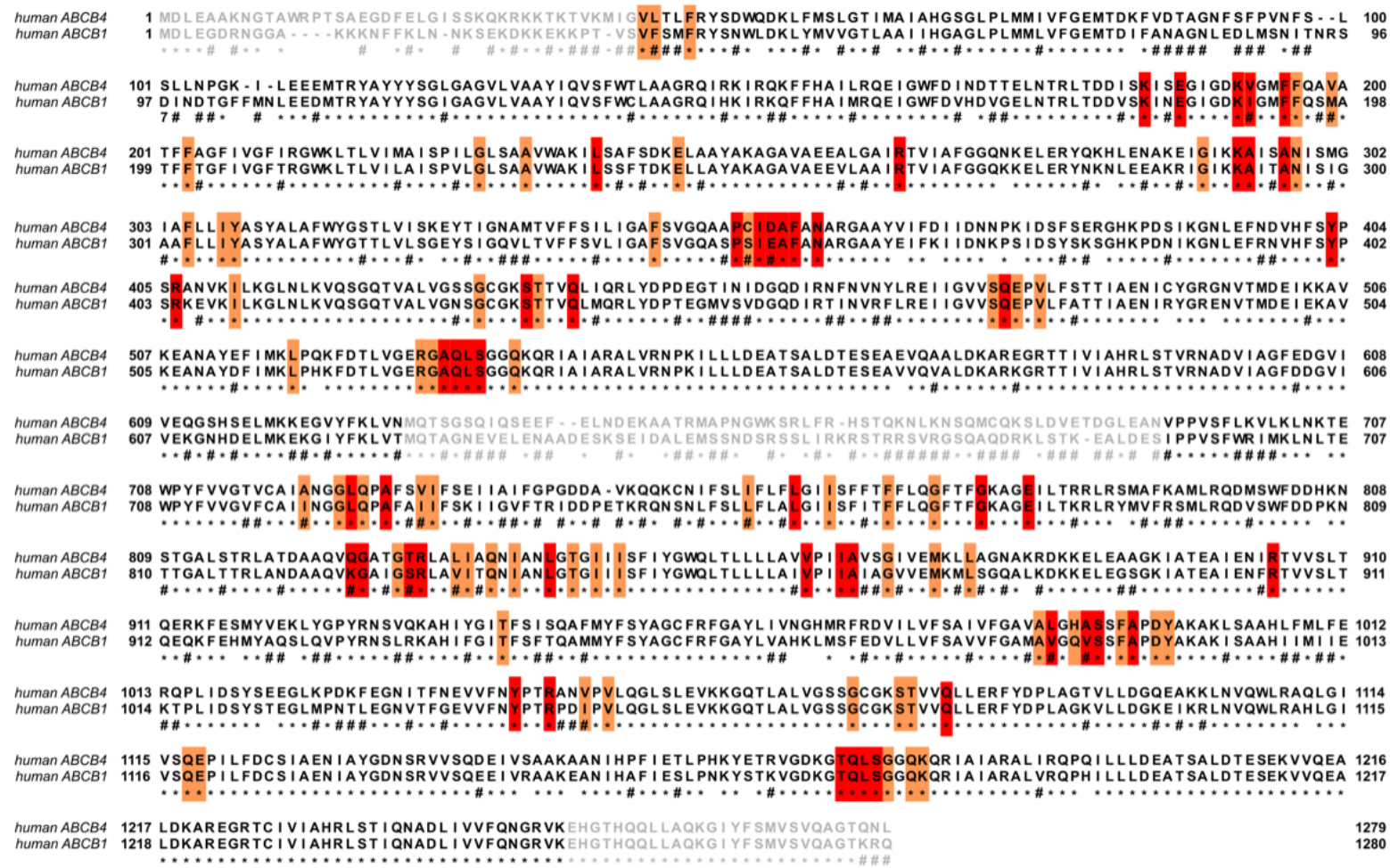

Supplementary Figure S1. Sequence alignment of human ABCB4 and human ABCB1. The protein sequences of human ABCB4 (NP_000434.1) and ABCB1 (NP_000918.2) were aligned using the Uniprot alignment tool (https://www.uniprot.org/align/) and represented using Jalview software (https://www.jalview.org/). Conservation of residues are represented as follows: *, identical; \# similar. Residues shown in Figure 5B are highlighted either in red for contact rates above $90 \%$ or in orange otherwise. Residues in grey $(\mathrm{N}$ - and $\mathrm{C}$-terminal domains and $\mathrm{L}_{1}$-linker) were not built in the $3 \mathrm{D}$ models. 


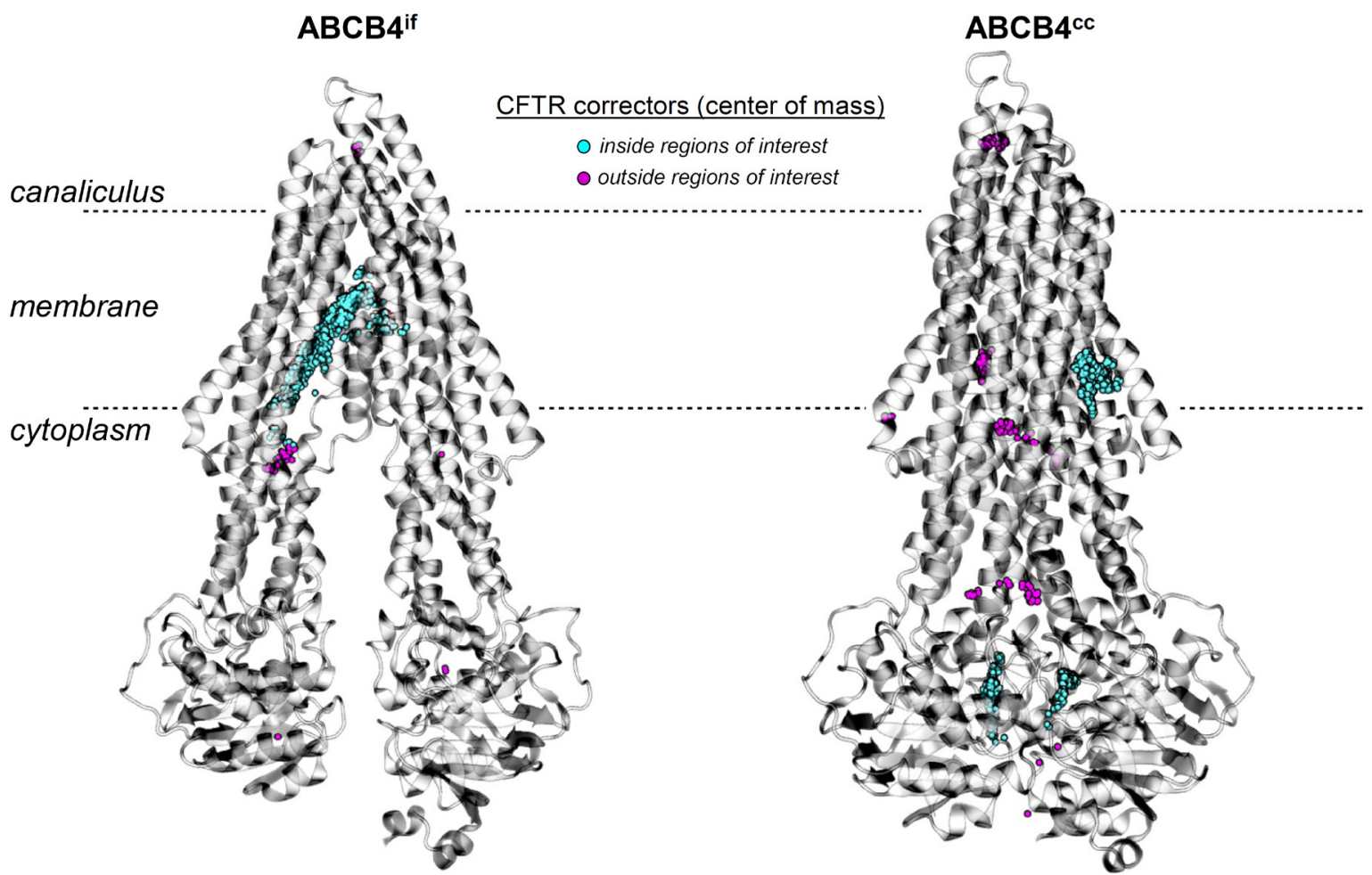

Supplementary Figure S2. Blind in silico molecular docking of CFTR correctors into ABCB4 ${ }^{\text {if }}$ and $\mathbf{A B C B} 4^{\text {cc }}$. Blind molecular docking simulations with CFTR correctors shown in Supplementary Table S1 were performed using the two indicated conformations of ABCB4 (see Materials and Methods for details). Four hundred poses from 20 independent simulations are displayed for each corrector. For the sake of clarity, only the corrector centers of mass are represented and color-coded according to their localization inside or outside the regions defined in Supplementary Table S2. Results from these analyses are summarized in Supplementary Table S3. 

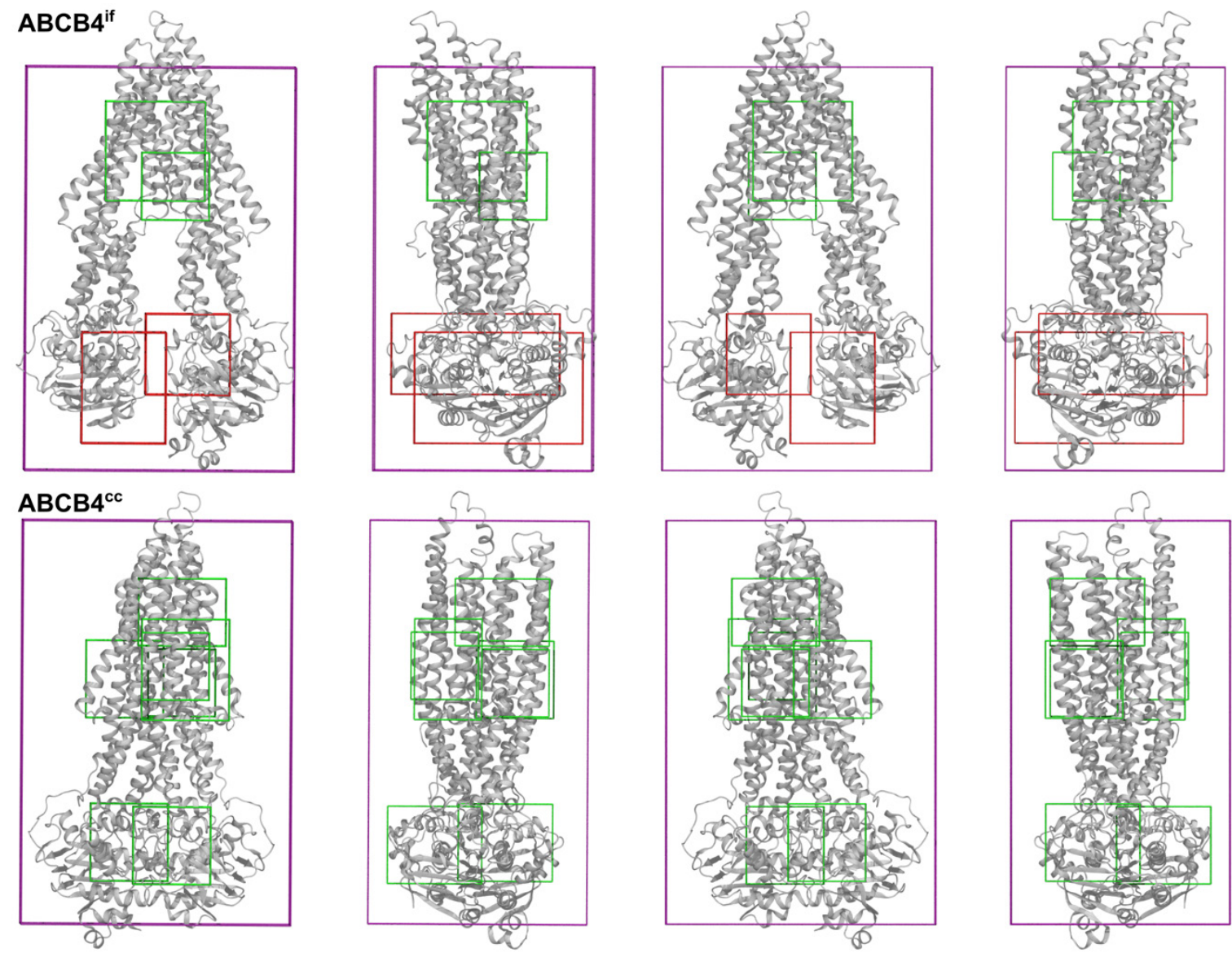

Supplementary Figure S3. Refined in silico molecular docking of CFTR correctors into ABCB4 ${ }^{\text {if }}$ and $\mathbf{A B C B}{ }^{\text {cc }}$. Refined molecular docking simulations with CFTR correctors shown in Supplementary Table S1 were performed using the two indicated conformations of ABCB4 (see Materials and Methods for details), for which regions were originally obtained from blind molecular docking calculations (boxes colored in purple). Regions obtained from $\mathrm{ABCB} 4^{\text {if }}$ were also sampled in $\mathrm{ABCB} 4^{\mathrm{cc}}$ and vice versa. Regions colored in red are regions which were sampled without exhibiting poses from refined molecular docking calculations while regions colored in green were further considered. 

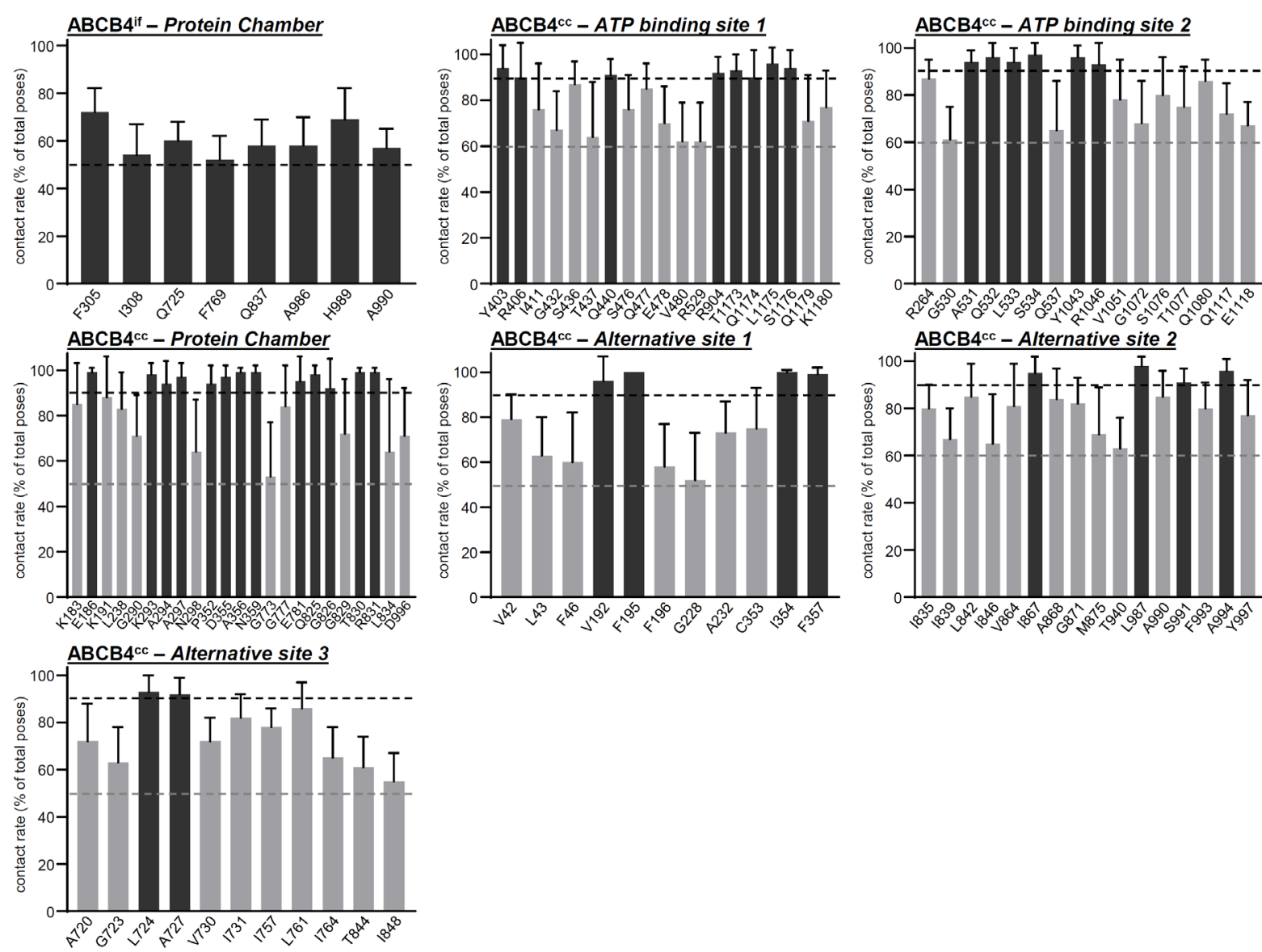

Supplementary Figure S4. Contact rates of ABCB4 residues with all CFTR correctors. The contact rates of ABCB4 residues identified in Figure 5B with all correctors shown in Supplementary Table S1 are represented. Dash lines indicate the cut-offs chosen for considering the involvement of the residues. Means ( \pm SD) of 20 independent simulations per CFTR corrector are shown. 

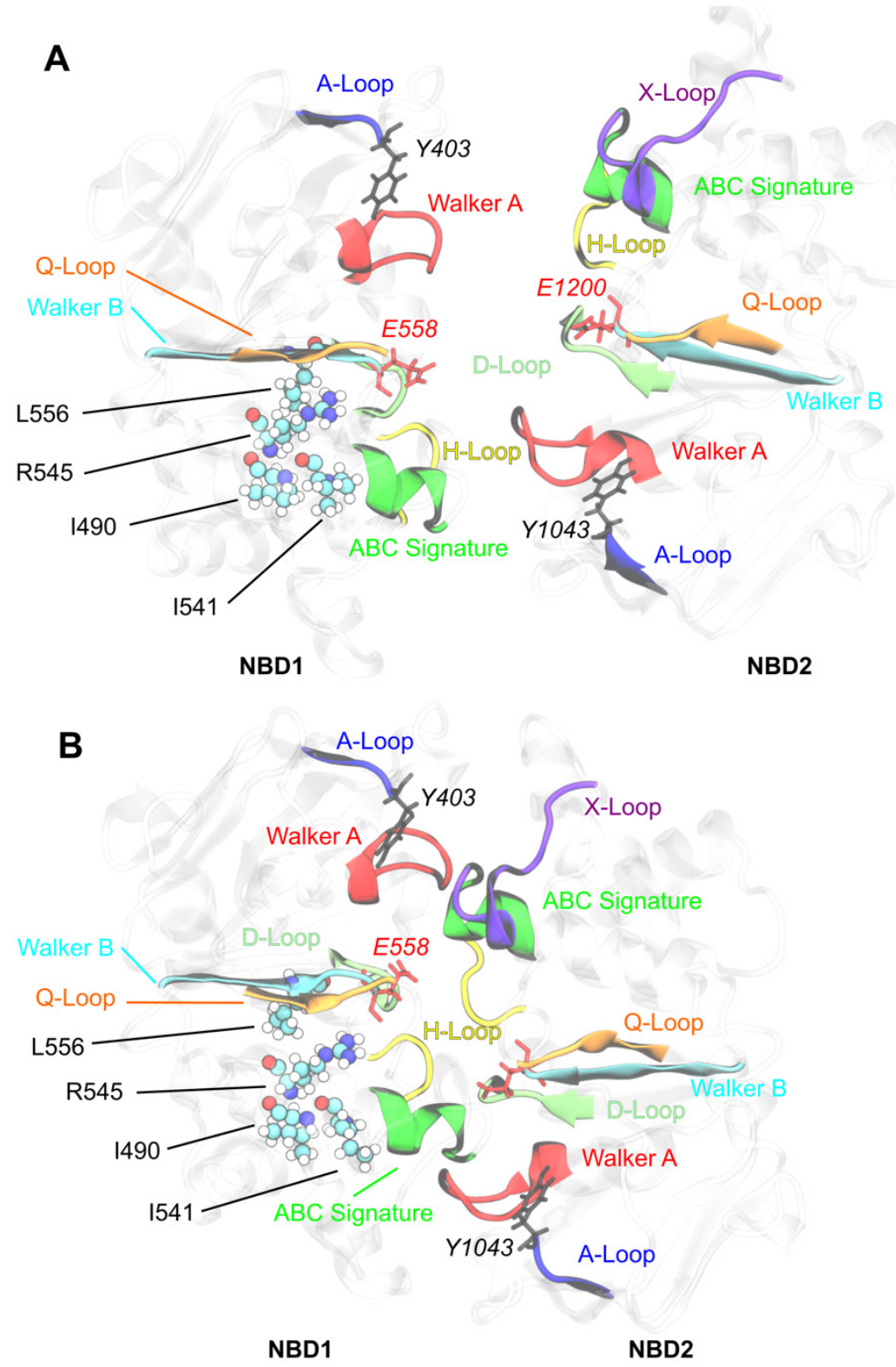

Supplementary Figure S5. Structural mapping of the I490, I541, R545 and L556 on $\mathbf{A B C B} 4^{\text {if }}$ (A) and $\mathbf{A B C B} 4^{\text {cc }}$ (B). Location of the four ABCB4 variants investigated in the present study (van der Waals representation, atom-type coloring), focusing on the NBDs. Key structural features of NBD are colored, as well as the catalytic glutamates (Glu558 and Glu1200, licorice representation, red) and adenosine-binding tyrosines (Tyr403 and Tyr1043, licorice representation, black). 


\section{SUPPLEMENTARY REFERENCES}

1. Lee J, Patel DS, Ståhle J, et al. CHARMM-GUI Membrane Builder for Complex Biological Membrane Simulations with Glycolipids and Lipoglycans. Journal of Chemical Theory and Computation. 2019;15(1):775-786.

2. Jo S, Kim T, Im W. Automated Builder and Database of Protein/Membrane Complexes for Molecular Dynamics Simulations. PLOS ONE. 2007;2(9):e880.

3. Jo S, Kim T, Iyer VG, Im W. CHARMM-GUI: A web-based graphical user interface for CHARMM. Journal of Computational Chemistry. 2008;29(11):1859-1865.

4. Jo S, Lim JB, Klauda JB, Im W. CHARMM-GUI Membrane Builder for Mixed Bilayers and Its Application to Yeast Membranes. Biophysical Journal. 2009;97(1):50-58.

5. D.A. Case, I.Y. Ben-Shalom, S.R. Brozell, et al. AMBER 2018. University of California, San Francisco 2018.

6. Skjevik AA, Madej BD, Dickson CJ, Teigen K, Walker RC, Gould IR. All-atom lipid bilayer self-assembly with the AMBER and CHARMM lipid force fields. Chemical Communications. 2015;51(21):4402-4405.

7. Dickson CJ, Madej BD, Skjevik ÅA, et al. Lipid14: The Amber Lipid Force Field. Journal of Chemical Theory and Computation. 2014;10(2):865-879.

8. Salomon-Ferrer R, Case DA, Walker RC. An overview of the Amber biomolecular simulation package. Wiley Interdisciplinary Reviews: Computational Molecular Science. 2013;3(2):198-210.

9. Kim S, Chen J, Cheng T, et al. PubChem 2019 update: improved access to chemical data. Nucleic Acids Research. 2018;47(D1):D1102-D1109.

10. Zhao Y, Truhlar D. The M06 suite of density functionals for main group thermochemistry, thermochemical kinetics, noncovalent interactions, excited states, and transition elements: two new functionals and systematic testing of four M06-class functionals and 12 other functionals. Theoretical Chemistry Accounts: Theory, Computation, and Modeling (Theoretica Chimica Acta). 2008;120(1):215-241.

11. Roe DR, Cheatham TE. PTRAJ and CPPTRAJ: Software for Processing and Analysis of Molecular Dynamics Trajectory Data. Journal of Chemical Theory and Computation. 2013;9(7):3084-3095.

12. Nguyen H, Roe DR, Swails J, Case DA. Pytraj. 2015; https://github.com/AmberMD/pytraj.

13. Walt Svd, Colbert SC, Varoquaux G. The NumPy Array: A Structure for Efficient Numerical Computation. Computing in Science \& Engineering. 2011;13(2):22-30.

14. Oliphant T. Guide to Numpy. Trelgol Publishing USA; 2006.

15. Hunter JD. Matplotlib: A 2D Graphics Environment. Computing in Science \& Engineering. 2007;9(3):90-95.

16. Humphrey W, Dalke A, Schulten K. VMD: Visual molecular dynamics. Journal of Molecular Graphics. 1996;14:33-38.

17. Pedemonte N, Lukacs GL, Du K, et al. Small-molecule correctors of defective DeltaF508-CFTR cellular processing identified by high-throughput screening. J Clin Invest. 2005;115(9):2564-2571. 
18. Vertex Pharmaceuticals ${ }^{\mathrm{TM}}$ (https://www.vrtx.com/).

19. Van Goor F, Straley KS, Cao D, et al. Rescue of DeltaF508-CFTR trafficking and gating in human cystic fibrosis airway primary cultures by small molecules. Am J Physiol Lung Cell Mol Physiol. 2006;290(6):L1117-1130.

20. Hirth BH, Qiao S, Cuff LM, et al. Discovery of 1,2,3,4-tetrahydroisoquinoline-3carboxylic acid diamides that increase CFTR mediated chloride transport. Bioorg Med Chem Lett. 2005;15(8):2087-2091.

21. Robert R, Carlile GW, Pavel C, et al. Structural analog of sildenafil identified as a novel corrector of the F508del-CFTR trafficking defect. Mol Pharmacol. 2008;73(2):478-489.

22. Yoo CL, Yu GJ, Yang B, Robins LI, Verkman AS, Kurth MJ. 4'-Methyl-4,5'-bithiazolebased correctors of defective delta F508-CFTR cellular processing. Bioorg Med Chem Lett. 2008;18(8):2610-2614. 